13 Realised gains in stand volume of Eucalyptus globulus Labill. families at 7-9 years were

\section{Predicted genetic gain and realised gain in stand volume of Eucalyptus globulus}

\author{
A.N. Callister ${ }^{123^{*}}$, N. England ${ }^{4}$ and S. Collins ${ }^{4}$ \\ ${ }^{1}$ Treehouse Consulting, 2 Campbell Rd, Denmark WA 6333, Australia \\ ${ }^{2}$ Honorary Research Fellow, Department of Forest and Ecosystem Science, \\ University of Melbourne. Water Street, Creswick VIC 3363, Australia \\ ${ }^{3}$ Adjunct Research Fellow, Centre of Excellence in Natural Resource Management, The \\ University of Western Australia, PO Box 5771, Albany, WA 6332, Australia \\ ${ }^{4}$ Elders Forestry Limited, PO Box 1421, Albany WA 6331, Australia \\ *Corresponding author: andrew@ treehouseconsulting.com.au; phone +61 427482947
}

compared with gains predicted at 3.5 years. Gain predictions were based on height, diameter at breast height (DBH), sectional area, and stem volume for 153 full-sib families and 18 commercial checks in five-tree line plots on three West Australian sites. Singlesite narrow-sense heritability estimates were $0.12-0.24$ for height, $0.08-0.12$ for DBH, 0.09-0.13 for sectional area and 0.14-0.19 for stem volume. Genetic dominance effects were significant $(p<0.05)$ in most cases and the estimated dominance:additive genetic variance ratio was heterogeneous for height and $\mathrm{DBH}$.

Stand volume was measured for 93 of the same families and checks in 40-tree block plots on four sites. Heritability of stand volume was $0.25-0.76$, with an across-sites estimate of 0.41. Dominance effects were statistically absent at two sites. Estimated region-wide additive genetic correlations between selection traits (in line plots) and stand volume (in block plots) ranged from 0.86 to 0.90 . Estimated stand volume gain was $23 \%$ of the mean for the best $12 \%$ of families and $14 \%$ of the mean for the best $24 \%$ of families. Realised gain was under-estimated by predictions based on height, DBH, and sectional area, which had smaller coefficients of additive variation than did stem volume. It is concluded that although BLUP analysis of early-age height and DBH can provide for 
1 indirect selection on E. globulus stand volume, analysis of stem volume is required to 2 predict genetic gain at an appropriate scale.

3

4 Keywords (4-6): Eucalytus globulus; realised genetic gain; stand volume; predicted

5 genetic gain; genetic correlation, best linear unbiased prediction 


\section{Introduction}

2 A common goal of forest tree improvement is to increase harvest stand volume, usually

3 by indirect selection on stem size early in the rotation. Trials with small plots such as

4 lines or single trees are recommended for this purpose because they allow evaluation of

5 many genetic entries while providing good replication and control of environmental

6 variation (Magnussen 1993). The optimum selection age for pulpwood eucalypts has

7 been estimated at between 3 and 4 years (Greaves et al. 2003). However, such early data

8 from small-plot trials might not provide for an accurate prediction of genetic gains in

9 harvest stand volume. The scale of genetic effects may change through time and with

10 trial design (Foster 1989; Carson et al. 1999) and competition between entries in small

11 plots can either inflate heritability and/or gain estimates (Foster 1989; Vergara et al.

12 2004; Stanger et al. 2011) or cause size-related mortality leading to artificially depressed

13 heritability (Stackpole et al. 2010). Realised gains in stand volume must therefore be

14 determined using trials with large plots ('block plots') which represent the growing

15 environment of a commercial stand (Foster 1992; Foster and Knowe 1995).

17 Predicted genetic gains in harvest stand volume are commonly used for projecting yields

18 and wood supply, implementing index selection, and estimating the financial returns from

19 breeding. For softwood species with rotations of 30 years or more, early-rotation genetic

20 gains have been translated into harvest volume increments by incorporating genetic

21 values into empirical growth models (e.g. Hamilton and Rehfeldt 1994; Carson et al.

22 1999; Adams et al. 2006; Gould et al. 2008). A simpler method is to calculate genetic

23 gain as a percentage of the population mean in the selection trait. This approach been

24 applied to Eucalyptus globulus Labill. on a 10-year rotation (Sanhueza et al. 2002) and to

25 other species for comparing the predicted gain with realised gain at mid-rotation (Vergara

26 et al. 2004; Weng et al. 2008; Verryn et al. 2009; Ye et al. 2010).

28 Early-rotation measurements can be used to predict stand volume gain if genetic

29 correlations are large enough and the traits are expressed at an equivalent genetic scale.

30 There are few published estimates of genetic correlations between predicted and realised

31 gain in forest trees. Ye et al. (2010) studied 15-year old Pseudotsuga menziesii var. 
menziesii (Mirb.) Franco gains trials and reported a correlation of 0.77 between predicted

2 and realised gain amongst 20 families. This estimate was based on best linear unbiased

3 predictions (BLUPs) representing predicted breeding values for stem volume and least-

4 square means (LSMs) for stand volume in block-plots. Jansson et al. (1998) used linear

5 mixed models to jointly model Pinus sylvestris L family data from single-tree plots and

6 block plots and estimate the correlations between them. They reported additive genetic

7 correlations between stem volume in single-tree plots and stand volume in block plots

8 ranging from 0.63 to 0.99 , with an average of about 0.87 .

10 Predicted and realised gains have been compared using LSM volume of seed orchard

11 entries in block-plots and predictions based on the BLUPs of parents represented in the

12 deployment. In these cases, the seed orchard entries are comprised of seed from a whole

13 orchard which may have been rouged or they represent different classes of genetic gain

14 collected from an orchard. Following this approach, Verryn et al. (2009) reported an

15 average 14\% realised gain in stem volume of Eucalyptus grandis Hill ex Maiden. per

16 generation over three generations compared to a predicted 13\% gain. Ye et al. (2010)

17 reported a realised gain in stand volume of Pseudotsuga menziesii var. menziesii of 17\%

18 compared to a predicted $16 \%$ from analysis of single-tree plots. Poorer correspondence

19 between predicted and realised gain has also been reported. Weng (2008) found that

20 realised gain in stand volume of Pinus banksianna Lamb. following seed orchard rouging

21 was nearly one-third lower than predicted (realised gain of 13\% versus predicted gain

22 18\%). Similarly, average genetic gains in mean annual increment of Pinus elliottii

23 Engelm, var elliottii across 38 block-plot trials in southern USA were found to be almost

24 one-fifth lower than predicted for two breeding populations (Vergara et al. 2004).

E. globulus is a highly valued pulpwood plantation species and is the subject of advanced

27 genetic improvement programs. Growth improvement of E. globulus is commonly

28 achieved by selection on diameter at breast height (DBH) and height (e.g. Li et al. 2007;

29 Costa e Silva et al. 2009; Callister et al. 2011). We measured stand volume in a series of

30 four block-plot progeny trials of full-sib families in Western Australia after 7-9 years of a

31 10-year pulpwood rotation. The same families were represented in line-plot trials in the 
1 same region, which were measured for DBH and height at 3.5 years. The objectives of

2 the study were to (A) quantify the genetic control of stand volume at late-rotation in

3 block-plot trials; (B) estimate the genetic correlations between early-rotation stem size in

4 line plots and late-rotation stand volume in block plots and (C) compare predicted and

5 realised gain estimates using a range of individual-tree traits for the prediction.

\section{MATERIALS AND MEASUREMENTS}

\section{$8 \quad$ Breeding Population and Test Sites}

9 This study was based on a second-generation breeding population which was previously

10 described as 'EGP1' by Callister et al. (2011). The population consisted of 153 full-sib $E$.

11 globulus families representing 86 parents from seven Australian provenances (SE

12 Tasmania, W Tasmania, NE Tasmania, Furneaux Group, King Island, Gippsland, and

13 Otways) and a Portuguese and a Californian land race. The parents were first-generation

14 selections from 84 open-pollinated (OP) families collected from native trees and land-

15 race plus-trees. Two parents were selected from the same OP family in two instances.

16 The parents were mated using an incomplete factorial design which included crosses

17 within and between provenances/land races. There was no reciprocal crossing. Five

18 commercial bulk collections and 13 unselected open-pollinated native families were

19 included as 'checks'. The trials were established at seven locations in the south west of

20 Western Australia in 1999; three line-plot (or row-plot) trials (L1-3) and four block-plot

21 trials (B1-4; Figure 1; Table 1). The trial sites were within $200 \mathrm{~km}$ of each other and had

22 previously been used for agriculture. All full-sib families and checks were represented in

23 the line-plot series and a subset of 86 control-pollinated families and seven checks were

24 established in the block-plot series. From 22 to 86 full-sib families were measured at

25 each block-plot site (Table 1) and a total of 647 block-plots contributed data to this

26 analysis. The representation of genetic entries in block-plot trials was highly unbalanced.

27 For example, four families were each represented by 35 to 64 plots across the four trials,

28 while 30 families were represented by only one plot at one of the trials. 
2 The line-plot trials consisted of five replicates of 10 incomplete blocks. Each block

3 contained 18 to 21 five-tree plots to which control-pollinated families and checks were

4 randomly assigned. The block-plot trials were established with incomplete blocks of 16 to

520 block-plots. Each block plot was five rows wide and eight planting spaces long (40

6 planting spaces per plot). Tree spacing throughout was $5 \times 2.5 \mathrm{~m}\left(800 \mathrm{stems} \mathrm{ha}^{-1}\right)$ except

7 at site $\mathrm{B} 1$, where it was $5 \times 2.0 \mathrm{~m}\left(1000 \mathrm{stems} \mathrm{ha}^{-1}\right)$. Soils were typical for the region,

8 classified as duplex or gravelly duplex and greater than $3 \mathrm{~m}$ deep (Table 1). Anaerobic

9 subsoils occurred within $3 \mathrm{~m}$ depth at sites B2 and B4.

11 Climate information for each trial site was obtained by spatial interpolation of available

12 information from nearby weather stations using 'Data Drill' (Jeffrey et al. 2001). The

13 climate at all sites could be described as 'mediterranean' with hot, dry summers and cool,

14 wet winters. However, rainfall across the region in the years following trial

15 establishment was less than the thirty-year average and ranged from an average 461

16 mm.year ${ }^{-1}$ at site L2 to 694 mm.year ${ }^{-1}$ at site B3 (Table 1). Pan evaporation was 2.3 to

173.3 times greater than rainfall (Table 1).

Data measurement and augmentation

20 Every tree in the line-plot trials was assessed for total height and diameter at $1.3 \mathrm{~m}$

21 (breast height; DBH) at 3.5 years. On trees with two stems (incidence less than 4\%), the

22 DBH of both stems was measured and entered as the square root of the sum of the

23 squares. Sectional area at breast height was calculated from DBH assuming each stem

24 was circular. Block-plots were measured at 9 years at sites B1, B3, and B4 and at 7 years

25 at site B2. DBH of all trees was measured. At site B2, the height of all plot trees in the

2618 central planting positions was measured. At B1, B3 and B4, heights of a subsample of

27 nine trees per plot were measured, comprising the six trees in the plot centre and the three

28 largest remaining trees (total $n=4650$ ). The following fixed-effects model was fitted to

29 these data using Genstat Version 13 (VSN International, UK): 
$1[1] \mathrm{HT}_{\mathrm{ijk}}=\mu+\mathrm{DBH}_{\mathrm{ijk}}+\mathrm{Fam}_{\mathrm{i}}+\mathrm{Block} / \mathrm{Site}_{\mathrm{j}}+\mathrm{Fam}_{\mathrm{i}} \cdot \mathrm{DBH}_{\mathrm{ijk}}+\mathrm{Block} / \mathrm{Site}_{\mathrm{j} .} \cdot \mathrm{DBH}_{\mathrm{ijk}}+e_{\mathrm{ijk}}$,

3 where $\mathrm{HT}_{i j k}$ and $\mathrm{DBH}_{i j k}$ are height and $\mathrm{DBH}$ of the $k^{\text {th }}$ tree from the $i^{\text {th }}$ family in the $j^{\text {th }}$

4 incomplete block, $F_{a m}$ and Block/Site $j$ are direct effects of the $i^{\text {th }}$ family and the $j^{t^{\text {th }}}$

5 incomplete block (nested within site) on height, Fam $_{i}$. $\mathrm{DBH}_{i j k}$ and Block/Site $j$. $\mathrm{DBH}_{i j k}$ are

6 effects of the $i^{\text {th }}$ family and the $j^{\text {th }}$ incomplete block (nested within site) on the slope of

7 relationship between $\mathrm{HT}$ and $\mathrm{DBH}$, and $e_{\mathrm{ijk}}$ is random error. Model [1] explained $75 \%$ of

8 observed variation in height and all fitted effects were significant $(p<0.001)$. Residual

9 plots confirmed that that the DBH-HT relationship was linear and residuals were

10 homoscedastic and normally distributed. The unmeasured heights of 14,746 trees at sites

11 B1, B3 and B4 were then predicted using their DBH measurements and the coefficients

12 estimated in fitting Model [1].

14 Total over-bark stem volume of each measured tree in each trial was calculated using the

15 following volume function which had been parameterized with data from West Australian

16 E. globulus trees ranging from $30 \mathrm{dm}^{3}$ to $400 \mathrm{dm}^{3}$ in volume:

$$
V_{\text {over-bark }}=0.1248\left(D B H_{\text {over-bark }}\right)^{1.3651} H^{1.1779}
$$

where $\mathrm{V}_{\text {over-bark }}$ is expressed in $\mathrm{dm}^{3}, \mathrm{DBH}_{\text {over-bark }}$ is measured in $\mathrm{cm}$ and tree height, $\mathrm{H}$, is 21 measured in $\mathrm{m}$.

23 Trees in the central 18 planting positions of each block-plot were identified at sites B2, 24 B3, and B4 and formed the basis for all subsequent analyses at those sites. Trees on the 25 periphery of block-plots were excluded to remove potential competition from adjacent 26 plots. The within-plot positions of trees were poorly identified during the measurement 27 at site B1, so all trees at site B1 contributed to subsequent analyses. Stand volume $\left(\mathrm{m}^{3}\right.$ $28 \mathrm{ha}^{-1}$ ) was calculated for each block-plot by summing tree volumes and dividing by the 29 plot area. 


\section{ANALYSES AND RESULTS}

2 The general statistical framework of genetic analyses

3 Genetic analyses were conducted using ASReml version 3.0 (Gilmour et al. 2009) within

4 the framework of the general linear mixed model:

$6 \quad[3] \quad \mathbf{y}=\mathbf{X b}+\mathbf{Z u}+\mathbf{e}$

8 where $\mathbf{y}$ is the vector of observed values for the response variable, sorted by site for

9 multi-site analyses; $\mathbf{b}$ and $\mathbf{u}$ are vectors of fixed and random effects, respectively, $\mathbf{Z}$ and

$10 \mathbf{X}$ are incidence matrices relating observations to model effects and $\mathbf{e}$ is the vector of

11 residuals. The distribution of random effects was assumed to be multivariate normal with

12 means and (co)variances defined by:

$$
\left[\begin{array}{l}
\mathbf{u} \\
\mathbf{e}
\end{array}\right] \sim N\left(\left[\begin{array}{l}
\mathbf{0} \\
\mathbf{0}
\end{array}\right],\left[\begin{array}{ll}
\mathbf{G} & \mathbf{0} \\
\mathbf{0} & \mathbf{R}
\end{array}\right]\right)
$$

16 where $\mathbf{G}$ and $\mathbf{R}$ are the (co)variance matrices relating to $\mathbf{u}$ and $\mathbf{e}$, respectively, and $\mathbf{0}$ is a

17 null matrix. Each of the $j$ effects in $\mathbf{u}$ were assumed to be mutually independent with

18 (co)variance $\mathbf{G}_{i}$, so that $\mathbf{G}=\oplus_{i=1}^{j} \mathbf{G}_{\mathbf{i}}$, where $\oplus$ denotes the direct sum operation.

19 Standard errors of functions of variance components were calculated in ASReml using an

20 approximation of a first-order Taylor series expansion (Gilmour et al. 2009).

Single-site analyses of stem size in line-plot trials

23 Methods

24 Height, DBH, sectional area, and stem volume data from line-plot trials were first

25 analysed using univariate, single-site mixed models to understand the genetic architecture

26 for selection (line-plot) traits. We expected the variance functions for DBH and sectional

27 area to be almost identical, but that sectional area might be expressed on a larger scale.

28 In each model, the terms in $\mathbf{b}$ comprised fixed effects for the mean, replicates, and

29 checks. The random terms in $\mathbf{u}$ represented provenance effects of parents with the design 
1 matrices for the maternal and paternal provenances overlaid upon each other, general

2 combing ability (GCA) given by overlaying the design matrices for the maternal and

3 paternal parents, specific combining ability (SCA) given by family-specific effects, plot

4 effects, trial design effects of factors blocks, rows, and columns, and a term for additional

5 within-plot variance of checks. Residuals were generally decomposed into spatially

6 dependent $(\xi)$ and spatially independent $(\eta)$ components according to:

$7 \quad \mathbf{R}=\sigma_{\xi}^{2}\left[A R 1\left(\rho_{\text {col }}\right) \otimes A R 1\left(\rho_{\text {row }}\right)\right]+\sigma_{\eta}^{2} \mathbf{I}_{\mathbf{n}}$, where $\sigma_{\xi}^{2}$ and $\sigma_{\eta}^{2}$ are spatially dependent and

8 spatially independent residual variances, respectively, $\otimes$ is the Kronecker product and

$9 \quad A R 1(\rho)$ represents a first-order autoregressive correlation matrix (Cullis and Gleeson

10 1991; Dutkowski et al. 2006). No variance was explained by the spatial autocorrelation

11 process for DBH and sectional area at site L1. The significance of SCA effects was

12 determined with one-tailed likelihood ratio tests (LRTs) with $\chi_{0.5}^{2}$ (Stram and Lee 1994).

13 Additive genetic variance $\left(\sigma_{A}^{2}\right)$ was estimated as $4 \hat{\sigma}_{G C A}^{2}$, where $\hat{\sigma}_{G C A}^{2}$ is the estimated

14 GCA variance, dominance genetic variance $\left(\sigma_{D}^{2}\right)$ was estimated as $4 \hat{\sigma}_{S C A}^{2}$, where $\hat{\sigma}_{S C A}^{2}$ is

15 the estimated SCA variance, and phenotypic variance $\left(\sigma_{P}^{2}\right)$ was estimated as

$162 \hat{\sigma}_{G C A}^{2}+\hat{\sigma}_{S C A}^{2}+\hat{\sigma}_{\text {plot }}^{2}+\hat{\sigma}_{\text {block }}^{2}+\hat{\sigma}_{\text {row }}^{2}+\hat{\sigma}_{c o l}^{2}+\hat{\sigma}_{\eta}^{2}$, where $\hat{\sigma}_{\text {plot }}^{2}$ is the variance due to plots,

$17 \hat{\sigma}_{\text {block }}^{2}$ is the variance due to incomplete blocks, $\hat{\sigma}_{\text {row }}^{2}$ is the variance due to trial rows, and

$18 \hat{\sigma}_{c o l}^{2}$ is the variance due to trial columns. Coefficients of additive genetic variation $\left(C V_{A}\right)$

19 were estimated for each trait and site by $C \hat{V}_{A}=\hat{\sigma}_{A} / \bar{X}$, where $\bar{X}$ is the mean. Narrow-

20 sense heritabilities $\left(h^{2}\right)$ and dominance proportions $\left(d^{2}\right)$ were estimated for each trait at

21 each site by $\hat{h}^{2}=\hat{\sigma}_{A}^{2} / \hat{\sigma}_{P}^{2}$ and $\hat{h}^{2}=\hat{\sigma}_{D}^{2} / \hat{\sigma}_{P}^{2}$.

23 Results

$24 C \hat{V}_{A}$ was smallest for DBH (mean 0.057), followed by height (mean 0.073), sectional

25 area (mean 0.108), and stem volume (mean 0.141; Tables 2 and 3). Single-site $\hat{h}^{2}$ ranged

26 from 0.12 to 0.24 for height, 0.08 to 0.12 for $\mathrm{DBH}, 0.09$ to 0.13 for sectional area and

27 from 0.14 to 0.19 for stem volume (Tables 2 and 3). Estimated dominance genetic effects

28 were considerably smaller at site $\mathrm{L} 2$, where it was only significant for height $(p<0.05$; 
1 Table 2). Although $\hat{h}^{2}$ and $\hat{d}^{2}$ were nearly equivalent for $\mathrm{DBH}$ and sectional area, the

2 quadratic relationship between the traits resulted in $C \hat{V}_{A}$ for sectional area that were

3 nearly double those for DBH. Similarly, $\hat{h}^{2}$ and $\hat{d}^{2}$ for stem volume were generally

4 intermediate between those for height and $\mathrm{DBH}$, while $C \hat{V}_{A}$ for stem volume were more

5 than double the average $C \hat{V}_{A}$ for height and DBH.

6

[INSERT TABLES 2 AND 3 NEAR HERE]

9 The mean $\hat{\sigma}_{D}^{2}: \hat{\sigma}_{A}^{2}$ was 1.31 for height, 0.72 for $\mathrm{DBH}, 0.57$ for sectional area, and 0.64

10 for stem volume (Tables 2 and 3). SCA effects did not suggest the presence of between-

11 provenance heterosis. Provenance variance $\left(\hat{\sigma}_{P R O V}^{2}\right)$ was relatively small for all traits, as

12 indicated by the mean ratio $\hat{\sigma}_{P R O V}^{2}: \hat{\sigma}_{G C A}^{2}$ of 0.15 (Tables 2 and 3). No provenance

13 variance was found for height and stem volume at site L2, and in most cases the standard

14 error was larger than the provenance variance estimate (Tables 2 and 3).

\section{Multi-site analyses of stem size in line-plot trials}

17 Methods

18 Multi-site models were fitted to selection trait data to determine inter-site correlations and

19 heterogeneity in genetic variance ratios. These results were used to determine the best

20 model for data standardisation and to assist the interpretation of results from region-wide

21 analyses. Data for multi-site analyses were adjusted for spatial trends by subtracting

22 from $\mathbf{y}$ the row and column effects and spatial residuals. Five models (Lms-1 to Lms-5)

23 were then fitted to full-sib family data for each trait (Table 4). They contained effects of

24 site means and replicates in $\mathbf{b}$; parent provenances (overlaid design matrices), GCA

25 (overlaid design matrices), SCA, blocks and plots in $\mathbf{u}$. Genetic correlations were

26 constrained to be uniform between pairs of sites (as in Li et al. 2007; Costa e Silva et al.

27 2009). Further constraints on genetic (co)variances were varied between models to test

28 the hypotheses that inter-site SCA or GCA correlations were 1 using LRTs with $\chi_{0.5}^{2}$ and

29 to test heterogeneity in the ratios $\hat{\sigma}_{P R O V}^{2}: \hat{\sigma}_{G C A}^{2}$ and $\hat{\sigma}_{S C A}^{2}: \hat{\sigma}_{G C A}^{2}$ using LRTs with $\chi_{2}^{2}$ 
1 (Table 4). There was insufficient provenance variance at site L2 to fit this term with

2 inter-site correlation.

3 [INSERT TABLE 4 NEAR HERE]

5 Results

6 Uniform among-sites correlation estimates in GCA ranged from 0.71 for sectional area to

$7 \quad 0.87$ for height and they were significantly different from 1 in each case (Table 5). On

8 the other hand, uniform correlations in SCA were only significantly different to 1 for

9 height $\left(r_{S C A} 0.63\right.$; Table 5). Ratios of $\hat{\sigma}_{P R O V}^{2}: \hat{\sigma}_{G C A}^{2}$ were not significantly heterogeneous

10 among sites for any trait $(p>0.05)$ and uniform estimates ranged from 0.04 for height to

110.15 for sectional area (Table 5). Ratios of $\hat{\sigma}_{S C A}^{2}: \hat{\sigma}_{G C A}^{2}$ were significantly heterogeneous

12 for height, DBH and sectional area due to smaller SCA variance at site L2 (Tables 2, 3,

13 and 5). Nevertheless, $\hat{\sigma}_{S C A}^{2}: \hat{\sigma}_{G C A}^{2}$ was not significantly heterogeneous for stem volume

14 ( $p>0.05$ ), for which the uniform estimate was 0.55 (Table 5).

16 [INSERT TABLE 5 NEAR HERE]

Region-wide analyses of stem size in line-plot trials

19 Methods

20 The region-wide analysis of each selection trait provided the breeding values for use in

21 selection and genetic-gain estimation. Site additive standard deviations from Model

22 Lms-5 (Table 4) were used to standardise the spatially adjusted data for scale effects. The

23 variance constraints in Lms-5 made it as close as possible to the region-wide model, in

24 which the standardised data were used. Re-scaled data $\left(\mathrm{x}_{\mathrm{adj}}\right)$ were also centred to the

25 respective trial mean $\left(\bar{x}_{i}\right): x_{a d j}=\left(x-\bar{x}_{i}\right) / \hat{\sigma}_{A_{i}}$. This standardisation procedure is

26 convenient because back-transformed breeding values (as a percentage of the population

27 mean) are obtained by simply multiplying BLUPs by $C \hat{V}_{A}$.

29 The region-wide models of height, DBH, sectional area, and stem volume each contained

30 effects of replicates within sites, and checks in $\mathbf{b}$. Effects of parent provenances, 
1 provenancexsite, GCA, GCAxsite, SCA, SCA×site, blocks-in-sites, plots-in-sites, and

2 additional within-plot effects for checks were included in $\mathbf{u}$ (using overlaid design

3 matrices for provenance, GCA and their site interaction effects). Residual variances were

4 heterogeneous. Average narrow-sense heritabilities $\left(h_{\text {ave }}^{2}\right)$ and dominance proportions

$5 \quad\left(d_{\text {ave }}^{2}\right)$ were estimated for each trait by:

$\left.6 \hat{h}_{\text {ave }}^{2}={ }^{4 \hat{\sigma}_{\mathrm{GCA}}^{2}} /\left(2 \hat{\sigma}_{\mathrm{GCA}}^{2}+\hat{\sigma}_{\mathrm{GCA} \times \mathrm{Site}}^{2}+\hat{\sigma}_{\mathrm{SCA}}^{2}+\hat{\sigma}_{\mathrm{SCA} \times \mathrm{Site}}^{2}+\sum_{i=1}^{3}\left(\hat{\sigma}_{\text {blocki }}^{2}+\hat{\sigma}_{\text {plot }}^{2}+\hat{\sigma}_{\text {error }}^{2}\right)\right] / 3\right)$

7 and $\left.\hat{d}_{\text {ave }}^{2}=4 \hat{\sigma}_{\mathrm{SCA}}^{2} /\left(2 \hat{\sigma}_{\mathrm{GCA}}^{2}+\hat{\sigma}_{\mathrm{GCA} \times \mathrm{Site}}^{2}+\hat{\sigma}_{\mathrm{SCA}}^{2}+\hat{\sigma}_{\mathrm{SCA} \times \mathrm{Site}}^{2}+\sum_{i=1}^{3}\left(\hat{\sigma}_{\text {block }}^{2}+\hat{\sigma}_{\text {plot }}^{2}+\hat{\sigma}_{\text {error }}^{2}\right)\right] / 3\right)$

8 where genetic variances are estimated across sites, $\hat{\sigma}_{\text {block }}^{2}$ is block variance of the $i^{\text {th }}$ site,

$9 \hat{\sigma}_{\text {plot }}^{2}$ is plot variance of the $i^{\text {th }}$ site, and $\hat{\sigma}_{\text {error }}^{2}$ is the residual variance of the $i^{\text {th }}$ site.

11 Results

12 Region-wide average heritability estimates $\left(\hat{h}_{\text {ave }}^{2}\right)$ were 0.18 for height, 0.07 for DBH and 13 sectional area, and 0.14 for stem volume (Table 6). Region-wide $\hat{\sigma}_{D}^{2}: \hat{\sigma}_{A}^{2}$ ranged from

140.38 for stem volume to 0.81 for DBH. Provenance effects were small at the region-wide 15 scale, with $\hat{\sigma}_{P R O V}^{2}: \hat{\sigma}_{G C A}^{2}$ ranging from 0.10 for height to 0.22 for DBH (Table 6).

[INSERT TABLE 6 NEAR HERE]

\section{Survival in block-plots}

20 Methods and Results

21 Variable survival in block-plots was examined for genetic effects and to provide a basis

22 for removing stand volume data that were significantly impacted by poor survival. The

23 proportion of surviving trees within each block-plot ranged from $23 \%$ to $100 \%$ with a

24 mean of 87\%. It was assumed to follow a binomial distribution and modeled, site by site, 25 with a generalized linear mixed model using a logit link function:

$$
\eta_{\mathrm{ijkl}}=\log [\pi /(1-\pi)]=\mu+\mathrm{B}_{k}+G C A_{i}+G C A_{j}+S C A_{i j}+e_{i j k l}
$$


2 where $\eta_{\mathrm{ijk}}$ is the link function, $\pi$ is the proportion of surviving trees, $\mu$ is the conditional

3 mean, $B_{k}$ is the fixed effect of the $k^{\text {th }}$ incomplete block, $G C A_{i}$ and $G C A_{j}$ are the random

4 effects of the $i^{\text {th }}$ maternal parent and $j^{\text {th }}$ paternal parent with overlaid design matrices,

$5 S C A_{i j}$ is the random effect of specific combining ability between parents $i$ and $j$, and $e_{i j k}$ is

6 the random residual with $\mathrm{N}\left(0, \sigma_{\mathrm{e}}^{2} \boldsymbol{I}\right)$. Data were excluded from plots in two drainage

7 lines which cut across site B4.

9 There was no detectable variance associated with parental or family genetic effects at any

10 of the block-plot sites. We therefore considered variable survival to be a nuisance in the

11 analysis of stand volume, and we sought to remove its effect by imposing site-specific

12 survival thresholds for the inclusion of stand volume data. A fixed-effects model was

13 fitted to data from each site separately using Genstat version 13 (VSN International, UK)

14 to determine the significance of survival to plot stand volume:

$$
V_{n k l}=\mu+S_{\mathrm{n}}+F_{k}+\mathrm{B}_{l}+e_{n k l}
$$

18 where $V_{n k l}$ is the stand volume of the $n^{\text {th }}$ plot, $\mu$ is the mean, $S_{n}$ is the survival of the $n^{\text {th }}$

19 plot, $F_{k}$ is the random effect of the $k^{\text {th }}$ family, $\mathrm{B}_{l}$ is the random effect of the $l^{\text {th }}$ block, and

$20 e_{n k l}$ is random error.

22 Survival was a significant determinant of stand volume at each site when all measured

23 plots were considered $(p<0.05)$. Data from plots with the poorest survival were then

24 excluded and the remaining data were re-analysed with Model [6]. If survival remained a

25 significant effect in the remaining data, plots with the next-poorest survival were

26 excluded and the remaining data were re-analysed. This process was repeated until

27 survival was not a significant effect in the analysis of remaining data $(p<0.05)$. The

28 lowest plot survival in the remaining data at the completion of this process was

29 considered to be the survival threshold for the site. 
1 Survival thresholds were found to be $63 \%$ at B1 and $78 \%$ at B2, B3, and B4. Stand

2 volume data from $5 \%$ to $11 \%$ of measured plots at each site were excluded from further

3 analyses because their survival was poorer than these thresholds.

$5 \quad$ Single-site analyses of stand volume in block-plot trials

6 Methods

7 The analysis of stand volume commenced at the single-site level to understand the

8 genetic architecture of this trait. Trial means and checks were included as fixed effects in

9 b, while random effects of the parent provenance, GCA, SCA, and incomplete block

10 effects were generally included in $\mathbf{u}$. Design matrices were overlaid for provenance and

11 GCA effects. SCA was not fitted at site B2, where only 22 families were measured. An

12 additional random term was fitted to within-plot variance of checks at sites B1, and B3,

13 the only trials in which checks were represented sufficiently to estimate this term.

14 Residuals at sites B1, B3 and B4 were decomposed into spatially dependent $(\xi)$ and

15 spatially independent $(\eta)$ components using the same first-order autoregressive structure

16 as for the line-plot trials (AR1×AR1), except that in this case the experimental units were

17 plots rather than trees. Spatial analysis was not possible at site B2, where measured plots

18 were widely scattered amongst unmeasured plots.

20 Heritability of stand volume in block-plots was estimated by

$21 \hat{h}_{\text {STAND }}^{2}=4 \hat{\sigma}_{G C A}^{2} /\left(2 \hat{\sigma}_{\mathrm{GCA}}^{2}+\hat{\sigma}_{\mathrm{SCA}}^{2}+\hat{\sigma}_{\text {block }}^{2}+\hat{\sigma}_{\xi}^{2}+\hat{\sigma}_{\eta}^{2}\right)$, where terms are defined as for line-plot

22 analyses above. Dominance proportion of stand volume in block plots was estimated by:

$23 \hat{d}_{\text {STAND }}^{2}=4 \hat{\sigma}_{S C A}^{2} /\left(2 \hat{\sigma}_{\mathrm{GCA}}^{2}+\hat{\sigma}_{\mathrm{SCA}}^{2}+\hat{\sigma}_{\text {block }}^{2}+\hat{\sigma}_{\xi}^{2}+\hat{\sigma}_{\eta}^{2}\right) \cdot \hat{h}_{\text {STAND }}^{2}$ and $\hat{d}_{\text {STAND}}^{2}$ differ from narrow-

24 sense heritability and dominance proportion estimates because among-trees size variation

25 was averaged within plots and did not contribute to phenotypic variance. Although

26 spatial residual variance is not customarily included in the phenotypic variance

27 component (e.g. Ye and Jayawickrama 2008), it was included here to produce estimates

28 of variance components at the whole-of-site scale, which we considered to be appropriate

29 for deployed gain in stand volume. 
2 Results

3 Mean stand volume was $138 \mathrm{~m}^{3} \mathrm{ha}^{-1}, 79 \mathrm{~m}^{3} \mathrm{ha}^{-1}, 97 \mathrm{~m}^{3} \mathrm{ha}^{-1}$, and $92 \mathrm{~m}^{3} \mathrm{ha}^{-1}$ at sites B1 to

4 B4 respectively, corresponding to mean annual increment of $15.3 \mathrm{~m}^{3} \mathrm{ha}^{-1} \mathrm{y}^{-1}, 11.3 \mathrm{~m}^{3} \mathrm{ha}^{-1} \mathrm{y}^{-}$

$5{ }^{1}, 10.8 \mathrm{~m}^{3} \mathrm{ha}^{-1} \mathrm{y}^{-1}$, and $10.2 \mathrm{~m}^{3} \mathrm{ha}^{-1} \mathrm{y}^{-1}$, respectively. At sites B2, B3, and B4 genetic

6 variation in stand volume was overwhelmingly attributed to additive effects (GCA), with

7 nil estimated variance for SCA at sites B3 and B4, and nil or negligible variance for

8 provenance effects (Table 7). However, at site B1 genetic control of stand volume

9 followed a different pattern, whereby estimated provenance variance was nearly two-

10 thirds of $\hat{\sigma}_{G C A}^{2}$ and $\hat{\sigma}_{S C A}^{2}$ was large but not significant (Table 7). $\hat{h}_{\text {STAND }}^{2}$ ranged from 0.25

11 to 0.76 (Table 7), indicating that a substantial proportion of variance in late-rotation stand

12 volume was attributed to additive genetic variance. $C \hat{V}_{A}$ for stand volume ranged from

130.138 to 0.217 (mean 0.178 ).

15 [INSERT TABLE 7 NEAR HERE]

17 Multi-site analyses of stand volume in block-plot trials

18 Methods

19 Multi-site models were fitted to stand volume to determine inter-site correlations and

20 explore the best way to accommodate the larger provenance and SCA variances at site

21 B1. These results were used to determine the best model for data standardisation and

22 which terms to include in the region-wide and unified analyses. Data for multi-site

23 analyses of stand volume were adjusted for spatial trends at sites B1, B3, and B4 by

24 subtracting spatial residuals from $\mathbf{y}$. Six models (Bms-1 to Bms-6) were then fitted to

25 full-sib family data (Table 8). The models each included site mean effects in b;

26 heterogenous GCA effects (with overlaid design matrices) and block effects in $\mathbf{u}$. The

27 inconsistent partitioning of genetic variance at site B1 was examined by comparing the

28 Akaike information criterion (AIC) of models that included provenance and SCA only at

29 B1 with models that included provenance and SCA variance at each site as a uniform

30 ratio of GCA variance. The model sequence also allowed testing whether a uniform

31 between-site additive genetic correlation was significantly different from 1. 
2 [INSERT TABLE 8 NEAR HERE]

4 Results

5 The best multi-site model by AIC included provenance and SCA effects only at site B1

6 (Model Bms-1; Table 8). The uniform inter-site GCA correlation from this model was

$7 \quad 0.44$, which was significantly different from 1 ( $p<0.001$, LRT Bms-2 versus Bms-1 using

$8 \chi_{0.5}^{2}$ ). The omission of the provenance term at site B1 resulted in only a minor increase

9 of 0.5 in AIC (Model Bms-3; Table 8), so Bms-3 was adopted as the most parsimonious

10 multi-site model to form the basis of the proceeding with further analyses. Model Bms-4,

11 which included provenance and SCA effects as uniform proportions of GCA variance,

12 had an AIC 4.3 greater than model Bms-1, which included provenance and SCA only at

13 site B1 (Table 8). Comparison of models Bms-3 and Bms-6 showed that SCA variance at

14 site B1 was significant $\left(\mathrm{p}=0.02\right.$, LRT using $\left.\chi_{0.5}^{2}\right)$ when included with correlated GCA

15 effects in analysis of multi-site data.

17 Region-wide analysis of stand volume in block-plot trials

18 Methods

19 Region-wide analysis of stand volume was conducted to estimate the proportion of

20 phenotypic variance represented by additive genetic variance at a regional scale and as a

21 precursor to the unified GCA analyses. Full-sib family data were spatially adjusted and

22 standardised for scale effects using additive standard deviations from Model Bms-3. The

23 region-wide model included site means in $\mathbf{b}$ and a single variance for GCA, SCA at site

24 B1, GCAxsite interaction, and site-specific block effects in $\mathbf{u}$. Site residuals were

25 heterogeneous. Across-sites average heritability in stand volume $\left(h_{S T A N D_{\text {ave }}}^{2}\right)$ was

26 estimated as: $\hat{h}_{S T A N D_{\text {ave }}}^{2}=4 \hat{\sigma}_{\mathrm{GCA}}^{2} /\left(2 \hat{\sigma}_{\mathrm{GCA}}^{2}+\hat{\sigma}_{\mathrm{GCA} \times \mathrm{Site}}^{2}+\left[\hat{\sigma}_{\mathrm{SCA}(\mathrm{SiteB} 1)}^{2}+\sum_{i=1}^{4}\left(\hat{\sigma}_{\text {blocki }}^{2}+\hat{\sigma}_{\text {error }}^{2}\right)\right] / 4\right)$.

28 Results 
1 Additive genetic variance in stand volume was an appreciable proportion of total variance

2 at the regional scale, with $\hat{h}_{S T A N D_{\text {me }}}^{2}$ of 0.41 (Table 9). GCA $\times$ site variance was more than

$350 \%$ greater GCA variance, which is expected from the uniform across-sites GCA

4 correlation estimate of 0.44 reported above.

[INSERT TABLE 9 NEAR HERE]

Unified GCA analyses of line- and block-plot data

9 Methods

10 Joint analyses of GCA using data from both plot types ('unified GCA' analyses) were

11 undertaken to estimate genetic correlations between individual-tree selection traits at age

123.5 years and stand volume at age 7-9 years. Four models were fitted with correlations at

13 the site scale, each including one selection trait and stand volume. Line-plot and block-

14 plot data representing full-sib families were adjusted only for spatial trend, as previously

15 described. The models included all trial means and replicates within line-plot trials in $\mathbf{b}$,

16 while $\mathbf{u}$ contained provenance effects for each line-plot trial, GCA for each trial, SCA for

17 each line-plot trial and at site B1, and block and plot effects at sites where they were

18 present. Provenance variance at line-plot trials was fitted as heterogeneous without inter-

19 site correlation and SCA correlations were heterogeneous between line-plot trials.

20 Design matrices were overlaid for provenance and GCA effects. GCA was modeled

21 with: (A) uniform correlation in the selection trait between sites, (B) uniform correlation

22 in stand volume between sites, and (C) uniform correlation between sites, between traits.

24 Four unified GCA models were fitted to estimate genetic correlations at the regional

25 scale. Each model included one selection trait and stand volume. The full-sib family data

26 were adjusted for spatial trend and for scale effects by additive standard deviation, as

27 previously described. All trial means and replicates within line-plots were included in $\mathbf{b}$,

28 while $\mathbf{u}$ contained one variance for provenance effects across line-plot trials, a variance

29 for GCA across each trial type, SCA at each individual line-plot trial and at site B1, and

30 block and plot effects at sites where they were present. SCA correlations were

31 heterogeneous between line-plot trials. Design matrices were overlaid for provenance 
1 and GCA effects. GCA effects were modeled with one inter-trait correlation which was

2 compared with 1 using LRT with $\chi_{0.5}^{2}$.

4 Results

5 The uniform additive genetic correlations between 3.5-year selection traits and late-

6 rotation stand volume at the site scale were 0.65 for height, 0.59 for $\mathrm{DBH}, 0.58$ for

7 sectional area, and 0.65 for stem volume (Table 10). Between-site genetic correlations

8 within traits were similar to those reported above. The additive genetic correlations

9 between 3.5-year selection traits and late-rotation stand volume at the regional scale

10 ranged from 0.86 for height to 0.90 for stem volume (Table 10). Each correlation was

11 significantly different to $1(p<0.05)$.

13 [INSERT TABLE 10 NEAR HERE]

15 Comparison of predicted and realised genetic gains

16 Methods

17 Although the above results demonstrate good genetic correlation between early-age

18 selection traits and late-rotation stand volume, differences in the scale of genetic effects

19 could result in very different estimates of genetic gain. Our final analysis was therefore

20 intended to compare the genetic gain of the best families in selection traits (i.e. predicted

21 gain) with realised gain of the same families in late-rotation stand volume.

23 BLUPs from region-wide models of line-plot data were used to estimate values for

24 provenance, GCA and SCA in units of additive standard deviation. The predicted genetic

25 value of each family was calculated for height, $\mathrm{DBH}$, sectional area, and stem volume by

26 summing the relevant provenance, GCA, and SCA values and multiplying the result by

27 the mean $C \hat{V}_{A}$ of the three line-plot trials ( 0.073 for height, 0.057 for DBH, 0.108 for

28 sectional area, and 0.141 for stem volume).

30 Genetic entries in block-plot trials were considered (perhaps counterintuitively) to be

31 fixed effects represented by least-square means (LSMs) for stand volume. This 
1 distinction from our preceding analyses of random genetic effects is important because

2 LSMs are less conservative than BLUPs and they will produce larger estimates of genetic

3 gain when sample sizes are relatively small (as is the case here). The statistical literature

4 does not provide a consistent view on how to judge an effect to be considered fixed or

5 random, or even how the terms are defined (Gelman 2005). McCulloch et al. (2011;

6 Sect 1.6b) provides the following guidance: "In endeavoring to decide whether a set of

7 effects is fixed or random, the context of the data, the manner in which they were

8 gathered and the environment from which they came are the determining factors... are

9 the levels of the factor going to be considered a random sample from a population of

10 values which have a distribution?" In our case, the families which were entered into

11 block-plot trials could be considered as random representations of a distribution

12 representing all possible full-sib E. globulus families, and this formed the basis of the

13 preceding analyses. However, for estimating genetic gain, we considered the "context of

14 the data" differently. We considered a hypothetical scenario in which the full range of

15 families was tested in line-plots, measured at 3.5 years and represented by random

16 effects, or BLUPs. In this scenario, the best-ranked families were then deployed

17 commercially (mimicked by the block-plots in our experiment), prompting the question

18 'how well did we predict the realised genetic gain in our commercial stands?' In this

19 case, once those best families were selected for deployment they were no longer

20 considered to be drawn randomly from a distribution but rather they represented a

21 particular treatment with a fixed effect. It should be also noted that the experimental

22 errors in the block-plot analyses were independent of the errors adjusted for when making

23 BLUP estimates in line-plots. Treating families as fixed effects is comparable to an

24 assessment of inventory plots in which 'selected' and 'average' families were established.

26 Stand volume data were adjusted for spatial trend (as described above) and then divided

27 by the respective site mean. This simple transformation largely overcame site

28 productivity differences and the intuitive representation of stand volume as a percent of

29 the site mean is useful for making comparisons with predicted levels of genetic gain.

30 Representation of better- and poorer-performing families across sites was sufficiently

31 balanced for bias to be negligible. The statistical model contained fixed effects for 
1 genetic entries and random effects for incomplete blocks. Families and checks with only

2 one or two block-plots were excluded from realised gain estimation as their LSMs were

3 considered to be too imprecisely estimated. The LSMs of the remaining 42 full-sib

4 families and four checks were compared with their predicted gain in height, DBH,

5 sectional area, and stem volume. The predicted and realised genetic gain of the best $12 \%$,

$624 \%$, and $50 \%$ of the 42 full-sib families were calculated as:

7 [7] Gain $=\frac{\sum_{i=1}^{n} x_{i}}{n}-\frac{\sum_{j=1}^{42} x_{j}}{42}$,

8 where $x_{i}$ is the genetic value (either BLUP or LSM) of the $i^{\text {th }}$ family in an elite group of $n$

9 families on the basis of the selection variable (height, DBH, sectional area, or stem

10 volume), and $x_{j}$ is the genetic value (either BLUP or LSM) of the $j^{\text {th }}$ family in the entire

$11 \operatorname{group}(i \subseteq j)$.

13 Results

14 Realised genetic gain was around $23 \%$ for the best 5 families, $14 \%$ for the best 10

15 families, and 7\% for the best half of the group of 42 full-sib families (Table 11).

16 Predicted genetic gains varied with $C \hat{V}_{A}$ of the selection trait, from $4.7 \% \mathrm{DBH}$ gain to

$17 \quad 14.6 \%$ stem volume gain in the best 5 families (Table 11). This scale effect resulted in

18 under-predictions of genetic gain when using height, DBH, or sectional area (Table 11).

19 Genetic gain predictions were closest to realised gain estimates for stem volume; realised

20 gain was 8 percentage points greater than predicted for the best 5 families, 1.2 percentage

21 points greater than predicted for the best 10 families, and 0.3 percentage points smaller

22 than predicted for the best 21 families. The correlation between realised gain and

23 predicted gain in stem volume of individual full-sib families and checks was 0.82 (Figure

24 2). Agreement between predicted and realized gain was better for families and checks

25 with 10 or more block-plots (Figure 2), suggesting that some of the imprecision was due

26 to small sample size of block-plots.

28 Three checks were represented by more than 10 block-plots and realised gain for these

29 entries ranged from $-5.4 \%$ to $-1.5 \%$ of the population mean (Figure 2). Two of these 
1 entries were bulk collections from open-pollinated seed orchards and one was a collection

2 from a native stand which had performed well in previous trials.

4 Although we stand by our use of LSM estimates for realised gain, some readers will no

5 doubt be interested in the gains estimated if we had treated families as random effects.

6 As expected, we found that treating families as random resulted in smaller estimates of

7 gain, and that this reduction was dependent on the family sample size. Gain estimates for

8 families represented by more than 10 plots differed by less than $1.5 \%$ when treating

9 families as random. Gain estimates for families represented by 3 to 8 plots differed by up

10 to $13.3 \%$. The BLUP-based realised gain was $17.4 \%$ for the best 5 families, $10.2 \%$ for

11 the best 10 families, and $5.6 \%$ for the best 21 families ranked by 3.5 -year stem volume.

13 [INSERT TABLE 11 NEAR HERE]

15 [INSERT FIGURE 2 NEAR HERE]

\section{DISCUSSION}

19 Single-site $\hat{h}^{2}$ and $\hat{d}^{2}$ for DBH were comparable to previous estimates for full-sib $E$.

20 globulus in Australia (Volker 2002; Li et al. 2007) and DBH $\hat{h}^{2}$ was similar to the

21 average value of 0.12 from 40 Portuguese sites reported by Araujo et al. (2012). Single-

22 site $\hat{h}^{2}$ and $\hat{d}^{2}$ for height were within the range reported by Li et al. (2007). Previous

23 reports of genetic parameters for sectional area and stem volume are lacking for full-sib

24 E. globulus families. Inter-site $r_{G C A}$ estimates in selection traits between 0.71 and 0.87

25 suggest that additive genetic $\times$ site interaction is a not a major concern for the population

26 in this region, even though it may be statistically significant. Previous estimates of

27 additive genetic correlation in full-sib E. globulus DBH have been reported between 0.60

28 and 0.83 (Volker 2002; Li et al. 2007; Costa e Silva et al. 2009; Araujo et al. 2012). 
1 The genetic architecture of our population in Western Australia appears broadly similar

2 to that of another full-sib E. globulus population studied by Li et al. (2007) across sites

3 ranging from Tasmania and Victoria to Western Australia. Our estimate of 1.31 for a

4 uniform $\hat{\sigma}_{D}^{2}: \hat{\sigma}_{A}^{2}$ for height was similar to the value of 1.20 reported by Li et al. (2007)

5 although our estimate of 0.64 for DBH was smaller than their reported value of 1.00.

6 Like Li et al. (2007), we found that heterogeneity in $\hat{\sigma}_{D}^{2}: \hat{\sigma}_{A}^{2}$ was more significant for

7 height than for DBH and we also found that SCA effects were more site-dependent for

8 height than for DBH. The $\hat{\sigma}_{P R O V}^{2}: \hat{\sigma}_{G C A}^{2}$ estimates that we obtained were far smaller than

9 similar statistics reported by Li et al. (2007), who used the sub-race classification of

10 Dutkowski and Potts (1999). This suggests that some of the variance attributed to

11 additive effects in our analyses may have been distributed to subrace effects if we had

12 used the Dutkowski and Potts (1999) classification rather than coarser geographical

13 provenances and land races.

15 We found that stand volume in block-plots was under substantial additive genetic control, 16 with region-wide additive variance representing $41 \%$ of the phenotypic variance (given

17 by $\hat{h}_{S T A N D_{\text {ave }}}^{2}$ ). This result is crucial to commercial E. globulus improvement programs

18 which aim to increase harvest yield. $C \hat{V}_{A}$ for stand volume in our study (mean 0.18)

19 corresponded with those of Jansson (2007), who reported $C \hat{V}_{A}$ between 0.14 and 0.24

20 (mean 0.17) for fifteen block-plot family trials of Pinus sylvestris. $\hat{h}_{\text {STAND }}^{2}$ of stand

21 volume at sites B2 and B4 were larger than expected for $\hat{h}^{2}$ of a growth trait, due

22 probably to the lack of between-trees variance in the denominator. Unusually large

23 heritability estimates for stand volume were also calculated by Jansson et al. (1998), who

24 reported a mean of 0.59 from full-sib families of Pinus sylvestris at five block-plot trials.

Although the genetic correlations between early-age selection traits and stand volume are

27 of critical importance for effective yield improvement, they have rarely been quantified

28 due to the cost of implementing block-plot family trials. The uniform between-site $r_{G C A}$

29 estimates of 0.59 to 0.65 that we found between selection traits and stand volume (Table 
1 10) are at the low end of the range reported for the same traits in Pinus sylvestris ( 0.53 to

2 0.99; Jansson et al. 1998). The larger $r_{G C A}$ estimates of 0.86 to 0.90 at the regional scale

3 (Table 10) are more meaningful measures of the inter-trait correlations because they

4 relate to the breeding value estimates of stem size and of stand volume across the region.

6 Our inter-trait $r_{G C A}$ results suggest that height or DBH of line-plot entries were nearly as

7 good as stem volume for indirect selection on harvest stand volume. On the other hand,

8 predicted gains based on height were about half the realised gain and those based on

9 DBH were about a third of the realised gain. $\mathrm{CV}_{\mathrm{A}}$ of selection traits determines the scale

10 of predicted genetic gain from parent selection. For example, sectional area had a larger

$11 C \hat{V}_{A}$ than did DBH and it produced a less biased estimate of stand volume gain.

12 Nevertheless, we found that only stem volume was expressed on a scale suitable for

13 predicting stand volume gain. E. globulus breeders have published variances and

14 heritability estimates for DBH (e.g. Costa e Silva et al. 2009; Stackpole et al. 2010;

15 Araujo et al. 2012) and sometimes for DBH and height (e.g. Lopez et al. 2002; Li et al.

16 2007), but rarely for stem volume (c.f. Sanhueza et al. 2002). Our findings prompt a call

17 for publication of genetic parameters (including $\mathrm{CV}_{\mathrm{A}}$ ) for individual stem volume, as it

18 appears to be expressed on a scale more similar to that of stand volume.

20 Most of the published studies comparing predicted and realised gain have confounded the

21 issues of genetic correlation and scale by using a handful of seed orchard entries to

22 represent different levels of realised gain. In two cases volume gains have met or

23 surpassed predicted values (e.g. Verryn et al. 2009; Ye et al. 2010), and the correlation of

240.77 between predicted and realised gains for families reported by Ye et al. (2010) is

25 similar to our correlation of 0.82 (see Figure 2). In other cases, predicted gains have not

26 been achieved in comparable gains trials (e.g. Vergara et al. 2004; Weng et al. 2008).

27 One reason that realised gains might not meet predicted gains is that between-tree

28 competition in intimate genetic mixtures is not representative of block plantings where

29 individuals compete with genetically similar material. This complication may be

30 particularly evident amongst clones (e.g. Sharma et al. 2008; Stanger et al. 2011) and its 
1 effects were perhaps not apparent in our study due to the early assessment of line-plot

2 trials just before canopy closure and the onset of stronger competition. Another potential

3 problem with early-age predictions of gain is that percentage gain can decrease over time

4 when absolute gain is unchanging (e.g. see the gain predictions of Carson et al. 1999).

5 The trial sites in our study may not have expressed this phenomenon because they were

6 strongly water-limited and would not have grown much in the last half of the rotation.

8 E. globulus can be feasibly reproduced in large full-sib families (Collins and Callister

9 2010), presenting the prospect of single-family deployment to commercial plantations.

10 Such a strategy would be predicated on an assumption that gain predictions from line-plot

11 progeny trials were unbiased and precise. Although we found that region-wide stem

12 volume BLUPs formed unbiased estimates of genetic gain in stand volume, the precision

13 of individual family gain predictions may be insufficient for single-family deployment.

14 For example, there were cases in which predicted gain of a well-represented family was

15 more than $10 \%$ below predicted gain (see Figure 2). Seed-based deployment of $E$.

16 globulus should therefore continue as family mixtures or as individual families only if a

17 reasonable number of families is represented in each commercial stand. These guidelines

18 will help to counter the risk that the genetic value of particular families is over-predicted.

20 We found that variable survival in block plots was not under measurable genetic control

21 and we removed its effect by setting thresholds for data exclusion. Another option was to

22 apply a model combining genetic effects and stocking (e.g. Jannsson et al. 1998), but we

23 found that too few plots were significantly affected by mortality to adequately

24 parameterize such a model. Stand volume of E. globulus in the trial region has

25 previously been found to be insensitive to stocking rates above about 600 stems ha $^{-1}$

26 (White et al. 2009). This is consistent with the survival thresholds that we applied, which

27 corresponded to around 630 stems $^{-1}$.

29 A number of outstanding issues could be addressed in further studies with improved

30 designs. We had too few block-plot sites to adequately understand the GCA×site

31 interaction in stand volume, and our study was limited to sites that were relatively poor 
1 for first-rotation E. globulus. Nevertheless, such sites were representative of a large

2 portion of the West Australian estate in the first rotation and they are likely to be more

3 typical of second-rotation sites due to water and nutrient depletion in the first rotation

4 (Mendham et al. 2011). An improved study design may feature adjacent line-plot and

5 block-plot family trials along productivity gradients and across regions, to better quantify

6 the effects of site and plot type on genetic correlations and the scale of genetic variation.

7 Results from a large experiment such as this may be suitable for developing a gain-

8 prediction tool based on integrated selection-age measurements and growth models. On

9 the other hand, our results do not suggest that a growth model is needed for genetic gain

10 prediction within a more limited environment. We were satisfied that the gain

11 predictions of the best $25 \%$ and $50 \%$ of families based on stem volume were unbiased,

12 and the gain under-prediction for the best $12 \%$ of families could be due to random

13 variation at the family level considering that only five families were represented in that

14 stratum. Our study was too small to form any reliable conclusions about the degree of

15 non-additive genetic control of stand volume. An experiment that aimed to reliably

16 define SCA effects on stand volume would need to be extremely large, considering that

17 the estimation of the dominance variance requires about 20 times as much data as for

18 additive variance, for equivalent accuracy (Misztal 1997).

\section{Conclusions}

21 We have found that late-rotation stand volume was under substantial additive genetic

22 control, with $\hat{h}_{\text {TTAND }_{\text {we }}}^{2}$ of 0.41 at the regional scale. Our results suggest that BLUP

23 analysis of early-rotation height, $\mathrm{DBH}$, or stem volume from line-plot progeny data

24 provides adequately for indirect selection on stand volume in E. globulus and that

25 predicted gains in stem volume are reasonable measures of stand volume gain. Predicted

26 gains in height or DBH were found to under-estimate stand volume gains due to scale

27 differences. Therefore, we recommend expressing E. globulus progeny trial data as stem

28 volume if unbiased genetic gain predictions are required and we encourage the

29 publication of genetic parameters for stem volume in addition to DBH and height. 


\section{Acknowledgments}

3 The authors acknowledge and thank the field staff who have assisted with establishing,

4 managing and measuring the 1999 Elders Forestry E. globulus trials; Wayne Davis, Keith

5 Smith, Shanu Nunn, Kristy Ratcliffe and Jacinta Baird. We are also grateful to two

6 anonymous reviewers who made important contributions to the improvement of this

7 manuscript.

\section{References}

10 Adams JP, Matney TG, Land SB, Belli KL, Duzan HW (2006) Incorporating genetic

11 parameters into a loblolly pine growth-and-yield model. Can J For Res 36

$12 \quad(8): 1959-1967$

13 Araujo JA, Borralho NMG, Dehon G (2012) The importance and type of non-additive genetic effects for growth in Eucalyptus globulus. Tree Genet Genom 8 (2):327-

16 Callister AN, England N, Collins S (2011) Genetic analysis of Eucalyptus globulus

Carson SD, Garcia O, Hayes JD (1999) Realized gain and prediction of yield with genetically improved Pinus radiata in New Zealand. For Sci 45 (2):186-200

Collins SL, Callister AN (2010) Genetic and environmental influences on capsule retention following hand pollination of Eucalyptus globulus flowers. Aust For 73 (3):198-203

Costa e Silva J, Borralho NMG, Araujo JA, Vaillancourt RE, Potts BM (2009) Genetic parameters for growth, wood density and pulp yield in Eucalyptus globulus. Tree Genet Genom 5:291-305

Cullis BR, Gleeson AC (1991) Spatial analysis of field experiments - an extension to two dimensions. Biometrics 47:1449-1460

29 Dutkowski GW, Potts BM (1999) Geographic patterns of genetic variation in Eucalyptus globulus ssp. globulus and a revised racial classification. Aust J Bot 47:237-263 
1 Dutkowski GW, Silva JCE, Gilmour AR, Wellendorf H, Aguiar A (2006) Spatial analysis 2 enhances modelling of a wide variety of traits in forest genetic trials. Can J For 3 Res 36 (7):1851-1870. doi:10.1139/x06-059

4 Foster GS (1989) Inter-genotypic competition in forest trees and its impact on realized 5 gain from family selection. Paper presented at the 20th Biennial Southern Tree 6 Breeding Conference, Charleston, SC, 26-30 June 1989

7 Foster GS (1992) Estimating yield: beyond breeding values. In: Finns L, Friedman ST, 8 Brotschol JV (eds) Handbook of Quantitative Forest Genetics. Kluwer Academic 9 Publishers, Dordrecht, pp 229-269

10 Foster GS, Knowe SA (1995) Deployment and genetic gains. Paper presented at the 11 Eucalyptus Plantations: Improving Fibre Yield and Quality, Hobart, 19-24 Feb

12 Gelman A (2005) Analysis of variance - Why it is more important than ever. Ann Stat 33 (1):1-31. doi:10.1214/009053604000001048

14 Gilmour AR, Gogel BJ, Cullis BR, Thompson R (2009) ASReml User Guide Release 3.0. 15 VSN International Ltd, Hemel Hempstead, HP1 1ES, UK,

16 Gould P, Johnson R, Marshall D, Johnson G (2008) Estimation of Genetic-Gain Multipliers for Modeling Douglas-Fir Height and Diameter Growth. For Sci 54 (6):588-596

Greaves BL, Borralho NMG, Raymond CA (2003) Early selection in eucalypt breeding in Australia - optimum selection age to minimise the total cost of kraft pulp production. New For 25 (3):201-210

Hamilton DA, Rehfeldt GE (1994) Using individual tree growth projection models to estimate stand-level gains attributable to genetically improved stock. For Ecol Man 68:189-207

Jansson G (2007) Gains from selecting Pinus sylvestris in southern Sweden for volume per hectare. Scand J For Res 22:185-192

Jansson G, Danell Ö, Stener L-G (1998) Correspondence between single-tree and multiple-tree plot genetic tests for production traits in Pinus sylvestris. Can J For 29 Res 28:450-458 
1 Jeffrey SJ, Carter JO, Moodie KM, Beswick AR (2001) Using spatial interpolation to 2 construct a comprehensive archive of Australian climate data. Environ Model 3 Softw 16 (4):309-330

4 Li Y, Dutkowski GW, Apiolaza LA, Pilbeam DJ, Costa e Silva J, Potts BM (2007) The 5 genetic architecture of a Eucalyptus globulus full-sib breeding population in 6 Australia. For Genet 12:167-179

7 Lopez GA, Potts BM, Dutkowski GW, Apiolaza LA, Gelid PE (2002) Genetic variation 8 and inter-trait correlations in Eucalyptus globulus base population trials in 9 Argentina. For Genet 9 (3):217-231

10 Magnussen S (1993) Design and analysis of tree genetic trials. Can J For Res 23:1144$11 \quad 1149$

12 McCulloch E, Searle SR, Neuhaus JM (2011) Generalized, Linear, and Mixed Models, 13 Second Edition. John Wiley \& Sons, 14 Mendham DS, White DA, Battaglia M, McGrath JF, Short TM, Ogden GM, Kinal J (2011) Soil water depletion and replenishment during first- and early secondrotation Eucalyptus globulus plantations with deep soil profiles. Agric For Meteorol 151:1568-1579

Misztal I (1997) Estimation of variance components with large-scale dominance models. J Dairy Sci 80:965-974

Sanhueza RP, White TL, Huber DA, Griffin AR (2002) Genetic parameters estimates, selection indices and predicted genetic gains from selection of Eucalyputs globulus in Chile. For Genet 9 (1):19-29

Sharma RK, Mason EG, Sorensson CT (2008) Productivity of radiata pine (Pinus radiata D. Don.) clones in monoclonal and clonal mixture plots at age 12 years. For Ecol Man 255 (1):140-148. doi:10.1016/j.foreco.2007.08.033

Stackpole DJ, Vaillancourt RE, de Aguiar M, Potts BM (2010) Age trends in genetic parameters for growth and wood density in Eucalyptus globulus. Tree Genet Genom 6 (2):179-193

Stanger TK, Galloway GM, Retief EC (2011) Final results from a trial to test the effect of plot size on Eucalyptus hybrid clonal ranking in Coastal Zululand, South Africa. South For 73 (3-4):131-135 
1 Stram DO, Lee JW (1994) Variance components testing in the longitudinal mixed effects $2 \quad$ setting. Biometrics 57:1138-1147

3 Vergara R, White TL, Huber DA, Shiver BD, Rockwood DL (2004) Estimated realized gains for first-generation slash pine (Pinus elliottii var. elliottii) tree improvement 5 in the southeastern United States. Can J For Res 34:2587-2600

6 Verryn SD, Snedden CL, Eatwell KA (2009) A comparison of deterministically predicted genetic gains with those realised in a South African Eucalyptus grandis breeding program. South For 71 (2):141-146

Volker PW (2002) Quantitative genetics of Eucalyptus globulus, E. nitens and their F1 hybrid. Ph.D. Thesis. PhD, Department of Botany, The University of Tasmania, Hobart, Tasmania,

Weng YH, Tosh K, Adam G, Fullarton MS, Norfolk C, Park YS (2008) Realized genetic gains observed in a first generation seedling seed orchard for jack pine in New Brunswick, Canada. New For 36 (3):285-298. doi:10.1007/s11056-008-9100-0

White DA, Battaglia M, Bruce J, Benyon R, Beadle C, McGrath J, Kinal J, Crombie S, Doody T (2009) Water-use efficient plantations - separating the wood from the leaves. Forest and Wood Products Australia Limited, Melbourne, Victoria

Ye TZ, Jayawickrama KJS (2008) Efficiency of using spatial analysis in first-generation coastal Douglas-fir progeny tests in the US Pacific Northwest. Tree Genet Genom 4 (4):677-692. doi:10.1007/s11295-008-0142-4

Ye TZ, Jayawickrama KJS, St Clair JB (2010) Realized gains from block-plot coastal Douglas-fir trials in the northern Oregon Cascades. Silvae Genet 59 (1):29-39 
1 Table 1. Summary of site conditions and other particulars for three line-plot (L) trials and

2 four block-plot (B) trials established 1999

\begin{tabular}{|c|c|c|c|c|c|c|c|}
\hline Trial code & L1 & L2 & L3 & B1 & B2 & B3 & B4 \\
\hline Trees per plot & 5 & 5 & 5 & 40 & 40 & 40 & 40 \\
\hline \multirow{2}{*}{ Locality } & Rocky & South & Manypeak & Bridget & Frankl & Napie & Manyp \\
\hline & Gully & Stirling & $\mathrm{s}$ & own & and & $\mathrm{r}$ & eaks \\
\hline Latitude & $34^{\circ} 31^{\prime}$ & $34^{\circ} 26^{\prime}$ & $34^{\circ} 43^{\prime}$ & $34^{\circ} 6^{\prime}$ & $34^{\circ} 21^{\prime}$ & $\begin{array}{l}34^{\circ} \\
46^{\prime}\end{array}$ & $34^{\circ} 45^{\prime}$ \\
\hline \multirow{2}{*}{ Longitude } & \multirow{2}{*}{$117^{\circ} 13^{\prime}$} & \multirow{2}{*}{$118^{\circ} 30^{\prime}$} & \multirow{2}{*}{$118^{\circ} 10^{\prime}$} & $116^{\circ}$ & $117^{\circ}$ & $117^{\circ}$ & $118^{\circ}$ \\
\hline & & & & $25^{\prime}$ & $12^{\prime}$ & $58^{\prime}$ & $12^{\prime}$ \\
\hline Soil Description: & $\begin{array}{l}\text { Gravelly } \\
\text { duplex }\end{array}$ & $\begin{array}{l}\text { Gravelly } \\
\text { duplex }\end{array}$ & Duplex & $\begin{array}{l}\text { Gravell } \\
\text { y } \\
\text { duplex }\end{array}$ & $\begin{array}{l}\text { Gravel } \\
\text { ly } \\
\text { duplex } \\
\text { anaero } \\
\text { bic } \\
\text { subsoi } \\
\text { ls }\end{array}$ & $\begin{array}{l}\text { Grav } \\
\text { elly } \\
\text { duple } \\
x\end{array}$ & $\begin{array}{l}\text { Duplex } \\
\text { anaero } \\
\text { bic } \\
\text { subsoil } \\
\text { s }\end{array}$ \\
\hline $\begin{array}{l}\text { Average Annual } \\
\text { Rainfall (mm })^{1}\end{array}$ & 605 & 461 & 598 & 592 & 503 & 694 & 598 \\
\hline Average & & & & & & & \\
\hline Evapn/Rainfall & 2.3 & 3.3 & 2.5 & 2.2 & 2.8 & 2.1 & 2.5 \\
\hline $\begin{array}{l}\text { CP Families in this } \\
\text { study }\end{array}$ & 153 & 143 & 148 & 49 & 22 & 86 & 41 \\
\hline $\begin{array}{l}\text { Measurement age } \\
\text { (years) }\end{array}$ & 3.5 & 3.5 & 3.5 & 9 & 7 & 9 & 9 \\
\hline Mean \pm SD Height $(m)$ & $8.8 \pm 1.6$ & $7.3 \pm 1.4$ & $10.2 \pm 1.8$ & $\begin{array}{l}15.8 \pm 2 . \\
9\end{array}$ & $\begin{array}{l}12.2 \pm \\
2.0\end{array}$ & $\begin{array}{l}14.6 \pm \\
2.3\end{array}$ & $\begin{array}{l}14.3 \pm 1 \text {. } \\
7\end{array}$ \\
\hline Mean \pm SD DBH $(\mathrm{cm})$ & $10.6 \pm 1.7$ & $8.2 \pm 1.8$ & $12.0 \pm 2.3$ & $\begin{array}{l}18.6 \pm 4 . \\
6\end{array}$ & $\begin{array}{l}13.4 \pm \\
3.0\end{array}$ & $\begin{array}{l}15.2 \pm \\
3.8\end{array}$ & $\begin{array}{l}15.1 \pm 3 . \\
1\end{array}$ \\
\hline
\end{tabular}

$3 \quad{ }^{1}$ From planting to measurement age 
1 Table 2. Estimates of variance components and functions from single-site analyses of

2 tree height and diameter at breast height in three line-plot trials (L1-L3) at age 3.5 years.

3 Estimated standard errors are in parentheses.

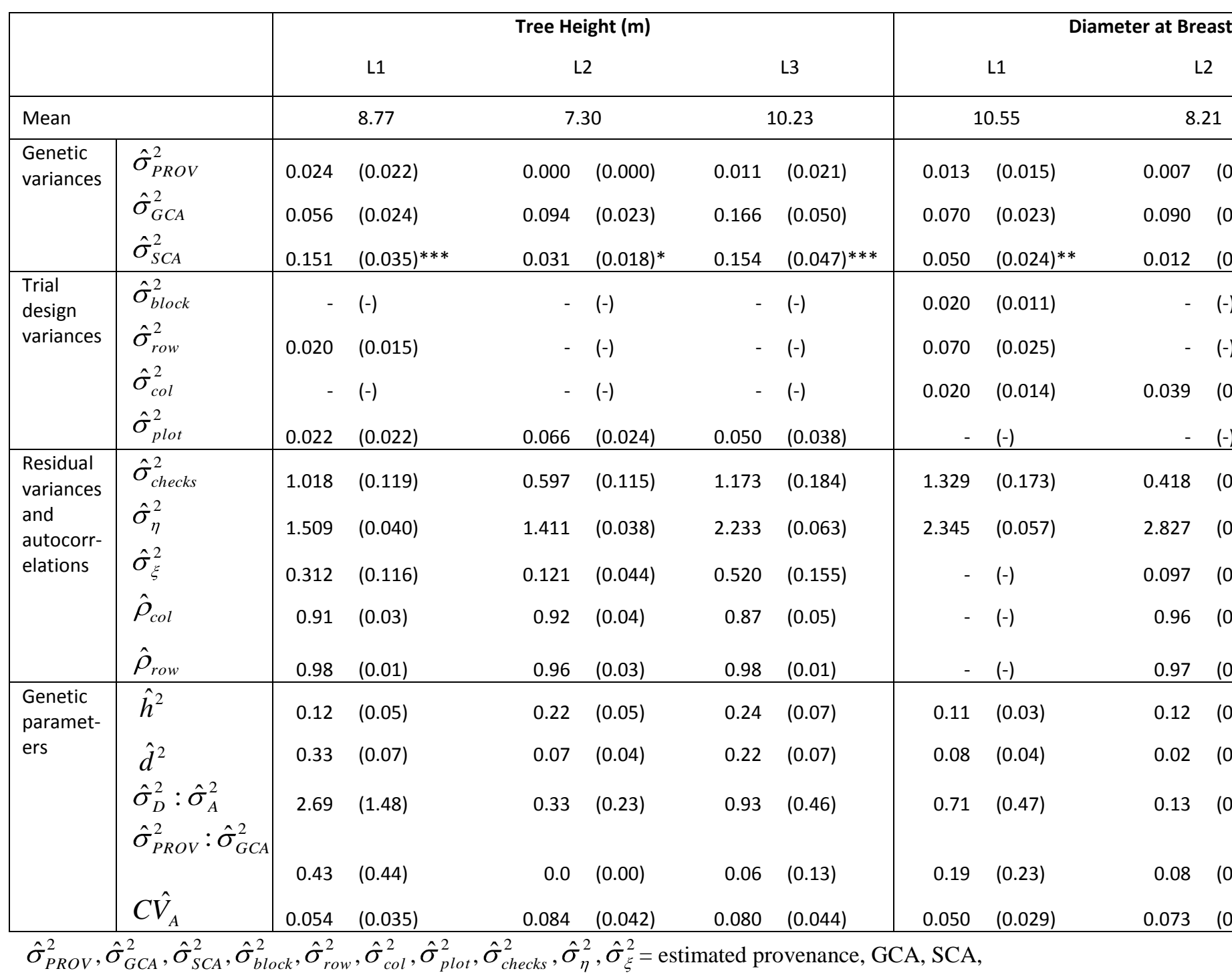

5 incomplete block, row, column, plot, additional checks residual, spatially independent residual, and spatial

6 residual variances, respectively; $\hat{\rho}_{c o l}, \hat{\rho}_{\text {row }}=$ estimated residual autocorrelation coefficients in the column

7 and row directions, respectively; $\hat{h}^{2}, \hat{d}^{2}, \hat{\sigma}_{D}^{2}: \hat{\sigma}_{A}^{2}, \hat{\sigma}_{P R O V}^{2}: \hat{\sigma}_{G C A}^{2}, C \hat{V}_{A}=$ estimated narrow-sense

8 heritability, dominance proportion, ratio of dominance variance to additive variance, ratio of provenance

9 variance to GCA variance, and coefficient of additive variation, respectively. Significance of $\hat{\sigma}_{S C A}^{2}$ by

$10 \quad$ LRT using $\chi_{0.5}^{2} p<0.05 *, p<0.01 * *, p<0.001 * * *$. Only non-zero variances are shown for trial design

11 factors. 
1 Table 3. Variance components and functions from single-site analyses of sectional area

2 and stem volume in three line-plot trials (L1-L3) at age 3.5 years. Estimated standard

3 errors are in parentheses.

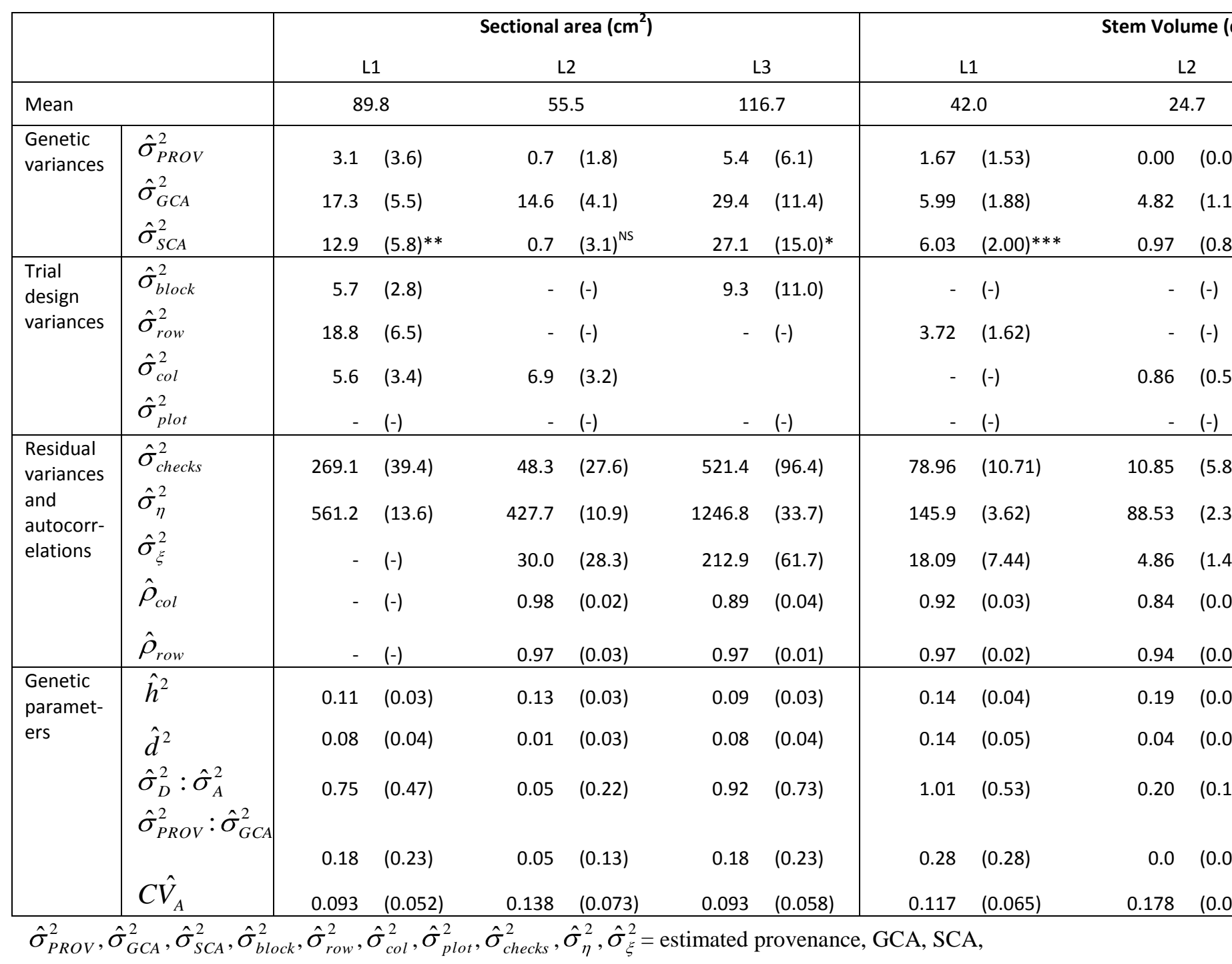

5 incomplete block, row, column, plot, additional checks residual, spatially independent residual, and spatial

6 residual variances, respectively; $\hat{\rho}_{c o l}, \hat{\rho}_{\text {row }}=$ estimated residual autocorrelation coefficients in the column

7 and row directions, respectively; $\hat{h}^{2}, \hat{d}^{2}, \hat{\sigma}_{D}^{2}: \hat{\sigma}_{A}^{2}, \hat{\sigma}_{P R O V}^{2}: \hat{\sigma}_{G C A}^{2}, C \hat{V}_{A}=$ estimated narrow-sense

8 heritability, dominance proportion, ratio of dominance variance to additive variance, ratio of provenance

9 variance to GCA variance, and coefficient of additive variation, respectively. Significance of $\hat{\sigma}_{S C A}^{2}$ by

10 LRT using $\chi_{0.5}^{2} p<0.05 *, p<0.01 * *, p<0.001 * * *$. Only non-zero variances are shown for trial design

11 factors. 
1 Table 4. Constraints applied to multi-site models to estimate inter-site genetic

2 correlations (Lms-1), to facilitate the testing of site $\times$ SCA interaction (Lms-1, -2), site $\times$

3 GCA interaction (Lms-1, -3 if $r_{S C A} \neq 1$ or Lms-2, -3 if $r_{S C A}=1$ ), heterogeneity in

$4 \hat{\sigma}_{P R O V}^{2}: \hat{\sigma}_{G C A}^{2}(\mathrm{Lms}-1,-4)$, and heterogeneity in $\hat{\sigma}_{S C A}^{2}: \hat{\sigma}_{G C A}^{2}(\mathrm{Lms}-4,-5)$.

\begin{tabular}{cccccccc}
\hline Model & $\hat{\sigma}_{\text {error }}^{2}$ & $\hat{\sigma}_{G C A}^{2}$ & $\hat{\sigma}_{P R O V}^{2}$ & $\hat{\sigma}_{S C A}^{2}$ & $r_{G C A}$ & $r_{\text {PROV }}$ & $r_{S C A}$ \\
\hline Lms-1 & $\mathrm{H}$ & $\mathrm{H}$ & $\mathrm{H}$ & $\mathrm{H}$ & $\mathrm{k}_{1}$ & 0 & $\mathrm{k}_{2}$ \\
Lms-2 & $\mathrm{H}$ & $\mathrm{H}$ & $\mathrm{H}$ & $\mathrm{H}$ & $\mathrm{k}_{1}$ & 0 & 1 \\
Lms-3 & $\mathrm{H}$ & $\mathrm{H}$ & $\mathrm{H}$ & $\mathrm{H}$ & 1 & 0 & $\mathrm{k}_{2}$ or 1 \\
Lms-4 & $\mathrm{H}$ & $\mathrm{H}$ & $\alpha \hat{\sigma}_{G C A}^{2}$ & $\mathrm{H}$ & $\mathrm{k}_{1}$ & 0 & $\mathrm{k}_{2}$ \\
Lms-5 & $\mathrm{H}$ & $\mathrm{H}$ & $\alpha \hat{\sigma}_{G C A}^{2}$ & $\beta \hat{\sigma}_{G C A}^{2}$ & $\mathrm{k}_{1}$ & 0 & $\mathrm{k}_{2}$ \\
\hline
\end{tabular}

$5 \mathrm{H}$ - heterogeneous variances across sites; $\mathrm{k}_{1}, \mathrm{k}_{2}-$ uniform across-site correlations

8 Table 5. Selected results from multi-site models of height, DBH, sectional area and stem

9 volume; uniform inter-site correlation in $\mathrm{GCA}\left(\mathrm{k}_{1}\right)$, uniform inter-site correlation in SCA

$10\left(\mathrm{k}_{2}\right)$, and constants in the ratios $\hat{\sigma}_{P R O V}^{2}: \hat{\sigma}_{G C A}^{2}$ and $\hat{\sigma}_{S C A}^{2}: \hat{\sigma}_{G C A}^{2}$ ( $\alpha$ and $\beta$, respectively).

11 Standard errors of correlations are in parentheses. Correlations were tested for

12 significance against $H_{0}: k_{i}=1$ using LRT with $\chi_{0.5}^{2}$. Ratio constants $\alpha$ and $\beta$ were tested

13 for heterogeneity using LRT with $\chi_{2}^{2}$.

\begin{tabular}{lcccccc}
\hline Trait & \multicolumn{2}{c}{$r_{G C A}\left(\mathrm{k}_{1}\right)$} & \multicolumn{2}{c}{$r_{S C A}\left(\mathrm{k}_{2}\right)$} & $\hat{\sigma}_{P R O V}^{2} / \hat{\sigma}_{G C A}^{2}(\alpha)$ & $\hat{\sigma}_{S C A}^{2} / \hat{\sigma}_{G C A}^{2}(\beta)$ \\
\hline Height & 0.87 & $(0.06)^{* *}$ & 0.63 & $(0.11)^{* * *}$ & $0.04^{\mathrm{NS}}$ & $1.31^{* * *}$ \\
DBH & 0.73 & $(0.10)^{* * *}$ & 1.00 & (bounded) & $0.14^{\mathrm{NS}}$ & $0.64^{*}$ \\
$\begin{array}{l}\text { Sectional } \\
\text { aras } \\
\text { Stem }\end{array}$ & 0.71 & $(0.09)^{* * *}$ & 1.00 & (bounded) & $0.15^{\mathrm{NS}}$ & $0.52^{*}$ \\
$\begin{array}{l}\text { Volume } \\
\mathrm{p}<0.05^{*}, \mathrm{p}<0.01^{* *}, \mathrm{p}<0.001 * * *\end{array}$ & 0.80 & $(0.07)^{* * *}$ & 0.87 & $(0.19)^{\mathrm{NS}}$ & $0.13^{\mathrm{NS}}$ & $0.55^{\mathrm{NS}}$ \\
\end{tabular}

15 
1 Table 6. Genetic and residual variance components and variance functions from region2 wide analyses of tree height, and DBH, sectional area and stem volume in line-plot trials 3 at age 3.5 years using standardised data. Estimated standard errors are in parentheses.

\begin{tabular}{|c|c|c|c|c|c|c|c|c|}
\hline \multirow{3}{*}{$\begin{array}{l}\hat{\sigma}_{P R O V}^{2} \\
\hat{\sigma}_{P R O V \times S i t e}^{2}\end{array}$} & \multicolumn{2}{|c|}{ Tree Height } & \multicolumn{2}{|c|}{ DBH } & \multicolumn{2}{|c|}{ Sectional area } & \multicolumn{2}{|c|}{ Stem Vol } \\
\hline & 0.028 & $(0.04)$ & 0.034 & $(0.04)$ & 0.031 & $(0.04)$ & 0.028 & $(0.03)$ \\
\hline & 0.000 & $(n / a)$ & 0.003 & $(0.01)$ & 0.006 & $(0.01)$ & 0.004 & $(0.01)$ \\
\hline$\hat{\sigma}_{G C A}^{2}$ & 0.265 & $(0.07)$ & 0.159 & $(0.05)$ & 0.167 & $(0.05)$ & 0.209 & $(0.05)$ \\
\hline$\hat{\sigma}_{G C A \times \text { Site }}^{2}$ & 0.028 & $(0.01)$ & 0.094 & $(0.03)$ & 0.085 & $(0.03)$ & 0.039 & $(0.02)$ \\
\hline$\hat{\sigma}_{S C A}^{2}$ & 0.153 & $(0.05)$ & 0.129 & $(0.04)$ & 0.095 & $(0.04)$ & 0.079 & $(0.03)$ \\
\hline$\hat{\sigma}_{S C A \times \text { Site }}^{2}$ & 0.167 & $(0.04)$ & 0.013 & $(0.04)$ & 0.032 & $(0.04)$ & 0.081 & $(0.03)$ \\
\hline$\hat{\sigma}_{\text {error(site_L1) }}^{2}$ & 4.464 & $(0.10)$ & 7.521 & $(0.18)$ & 7.035 & $(0.17)$ & 5.078 & $(0.12)$ \\
\hline$\hat{\sigma}_{\text {error(site_L2) }}^{2}$ & 6.237 & (0.17) & 9.933 & $(0.24)$ & 9.502 & $(0.23)$ & 5.983 & $(0.15)$ \\
\hline$\hat{\sigma}_{\text {error(site_L3) }}^{2}$ & 4.281 & $(0.11)$ & 8.957 & $(0.23)$ & 8.569 & $(0.22)$ & 5.520 & $(0.14)$ \\
\hline$\hat{h}_{\text {ave }}^{2}$ & 0.18 & $(0.04)$ & 0.07 & $(0.02)$ & 0.07 & $(0.02)$ & 0.14 & $(0.03)$ \\
\hline$\hat{d}_{\text {ave }}^{2}$ & 0.10 & $(0.03)$ & 0.06 & $(0.02)$ & 0.04 & $(0.02)$ & 0.05 & $(0.02)$ \\
\hline$\hat{\sigma}_{D}^{2}: \hat{\sigma}_{A}^{2}$ & 0.58 & $(0.26)$ & 0.81 & $(0.43)$ & 0.57 & $(0.33)$ & 0.38 & $(0.20)$ \\
\hline$\hat{\sigma}_{P R O V}^{2}: \hat{\sigma}_{G C A}^{2}$ & 0.10 & $(0.15)$ & 0.22 & $(0.26)$ & 0.19 & $(0.23)$ & 0.13 & $(0.16)$ \\
\hline
\end{tabular}

$5 \mathrm{GCA} \times$ site, SCA, SCA $\times$ site variances, respectively; $\hat{\sigma}_{\text {errorsite_L1) }}^{2}, \hat{\sigma}_{\text {error }(\text { site_L2) }}^{2}, \hat{\sigma}_{\text {error }(\text { site_L L3) }}^{2}=$

6 estimated residual variances for sites $\mathrm{L} 1, \mathrm{~L} 2$, and $\mathrm{L} 3$, respectively; $\hat{h}^{2}, \hat{d}^{2}, \hat{\sigma}_{D}^{2}: \hat{\sigma}_{A}^{2}, \hat{\sigma}_{P R O V}^{2}: \hat{\sigma}_{G C A}^{2}=$

7 estimated narrow-sense heritability, dominance proportion, ratio of dominance variance to additive

8 variance, and ratio of provenance variance to GCA variance, respectively.

9

10 
1 Table 7. Variance components and functions from single-site analyses of stand volume

2 in four block-plot trials. Estimated standard errors are in parentheses.

\begin{tabular}{|c|c|c|c|c|c|c|c|c|}
\hline & \multicolumn{2}{|c|}{ Site B1 } & \multicolumn{2}{|c|}{ Site B2 } & \multicolumn{2}{|c|}{ Site B3 } & \multicolumn{2}{|c|}{ Site B4 } \\
\hline Mean $\left(m^{3} h a^{-1}\right)$ & 138 & & 79 & & 97 & & 92 & \\
\hline$\hat{\sigma}_{P R O V}^{2}$ & 60 & (79) & 0 & (0) & 0 & (0) & 5 & (18) \\
\hline$\hat{\sigma}_{G C A}^{2}$ & 96 & $(114)$ & 74 & (38) & 45 & (19) & 98 & (38) \\
\hline$\hat{\sigma}_{S C A}^{2}$ & 324 & $(213)^{\mathrm{NS}}$ & $n / f$ & $(n / a)$ & 0 & $(0)$ & 0 & (0) \\
\hline$\hat{\sigma}_{\text {block }}^{2}$ & 273 & $(188)$ & 128 & (66) & 0 & (0) & 0 & (0) \\
\hline$\hat{\sigma}_{\text {checks }}^{2}$ & 302 & (355) & $n / f$ & (n/a) & 30 & (55) & $n / f$ & (n/a) \\
\hline$\hat{\sigma}_{\eta}^{2}$ & 305 & (78) & 115 & (25) & 83 & (34) & 105 & (28) \\
\hline$\hat{\sigma}_{\xi}^{2}$ & 438 & $(250)$ & $n / f$ & (n/a) & 320 & (86) & 277 & (87) \\
\hline$\hat{\rho}_{c o l}$ & 0.76 & $(0.18)$ & $n / f$ & (n/a) & 0.68 & $(0.11)$ & 0.68 & (0.14) \\
\hline$\hat{\rho}_{\text {row }}$ & 0.83 & $(0.12)$ & $n / f$ & (n/a) & 0.71 & $(0.11)$ & 0.81 & $(0.07)$ \\
\hline$\hat{h}_{\text {STAND }}^{2}$ & 0.25 & $(0.29)$ & 0.76 & $(0.28)$ & 0.36 & $(0.14)$ & 0.68 & $(0.21)$ \\
\hline$\hat{d}_{S T A N D}^{2}$ & 0.85 & $(0.55)$ & $n / f$ & $(n / a)$ & 0.00 & $(0.00)$ & 0.00 & $(0.00)$ \\
\hline$\hat{\sigma}_{D}^{2}: \hat{\sigma}_{A}^{2}$ & 3.39 & (5.67) & $n / f$ & (n/a) & 0.00 & $(0.00)$ & 0.00 & $(0.00)$ \\
\hline$\hat{\sigma}_{P R O V}^{2}: \hat{\sigma}_{G C A}^{2}$ & 0.63 & $(1.25)$ & 0.00 & $(0.00)$ & 0.00 & $(0.00)$ & 0.05 & (0.19) \\
\hline$C \hat{V}_{A}$ & 0.142 & $(0.155)$ & 0.217 & $(0.156)$ & 0.138 & $(0.089)$ & 0.215 & $(0.135)$ \\
\hline
\end{tabular}

$3 \hat{\sigma}_{P R O V}^{2}, \hat{\sigma}_{G C A}^{2}, \hat{\sigma}_{S C A}^{2}, \hat{\sigma}_{\text {block }}^{2}, \hat{\sigma}_{\text {checsks }}^{2}, \hat{\sigma}_{\eta}^{2}, \hat{\sigma}_{\xi}^{2}=$ estimated provenance, GCA, SCA, incomplete block,

4 additional checks residual, spatially independent residual, and spatial residual variances, respectively; $\hat{\rho}_{\text {col }}$,

$5 \hat{\rho}_{\text {row }}=$ estimated residual autocorrelation coefficients in the column and row directions, respectively;

$6 \hat{h}_{S T A N D}^{2}, \hat{d}_{S T A N D}^{2}, \hat{\sigma}_{D}^{2}: \hat{\sigma}_{A}^{2}, \hat{\sigma}_{P R O V}^{2}: \hat{\sigma}_{G C A}^{2}, C \hat{V}_{A}=$ estimated narrow-sense heritability of stand

7 volume, dominance proportion of stand volume, ratio of dominance variance to additive variance, ratio of

8 provenance variance to GCA variance, and coefficient of additive variation, respectively. Significance of

$9 \hat{\sigma}_{S C A}^{2}$ at B1 tested by LRT using $\chi_{0.5}^{2} ; \mathrm{n} / \mathrm{f}$ : not fitted.

10 
1 Table 8. Constraints applied to models to compare fitting provenance and SCA effects at 2 only Site B1 (Bms-1 to -3) with fitting them as a uniform proportion of $\hat{\sigma}_{G C A}^{2}$ (Bms-4,

3 Bms-5); to estimate across-sites genetic correlations (Bms-1, Bms-4); to test site $\times$ GCA 4 interaction (Bms-1,-2); to test SCA at site B1 (Bms-3,-6); to test SCA as a uniform 5 proportion of $\hat{\sigma}_{G C A}^{2}$ (Bms-5, -6); to test provenance at site B1 (Bms-1, -3), and to test 6 provenance as a uniform proportion of $\hat{\sigma}_{G C A}^{2}(\mathrm{Bms}-4,-5)$. The log-likelihood and change 7 in AIC (relative to Model 1) are presented for each model.

\begin{tabular}{|cccccc|cc|}
\hline Model & $\hat{\sigma}_{\text {error }}^{2}$ & $\hat{\sigma}_{G C A}^{2}$ & $r_{G C A}$ & $\hat{\sigma}_{\text {prov }}^{2}$ & $\hat{\sigma}_{S C A}^{2}$ & Log-L & $\Delta$ AIC \\
\hline Bms-1 & $\mathrm{H}$ & $\mathrm{H}$ & $\mathrm{k}_{1}$ & at B1 & at B1 & -1546.2 & 0.0 \\
Bms-2 & $\mathrm{H}$ & $\mathrm{H}$ & 1 & at B1 & at B1 & -1588.2 & 82.0 \\
Bms-3 & $\mathrm{H}$ & $\mathrm{H}$ & $\mathrm{k}_{1}$ & 0 & at B1 & -1547.4 & 0.5 \\
\hline Bms-4 & $\mathrm{H}$ & $\mathrm{H}$ & $\mathrm{k}_{1}$ & $\alpha \hat{\sigma}_{G C A}^{2}$ & $\beta \hat{\sigma}_{G C A}^{2}$ & -1548.4 & 4.3 \\
Bms-5 & $\mathrm{H}$ & $\mathrm{H}$ & $\mathrm{k}_{1}$ & 0 & $\beta \hat{\sigma}_{G C A}^{2}$ & -1548.4 & 2.4 \\
Bms-6 & $\mathrm{H}$ & $\mathrm{H}$ & $\mathrm{k}_{1}$ & 0 & 0 & -1549.6 & 2.8 \\
\hline
\end{tabular}

8

9 Table 9. Variance components and $\hat{h}_{S T A N D_{\text {Ne }}}^{2}$ from region-wide analysis of standardised 10 stand volume in four block-plot trials. Estimated standard errors are in parentheses.

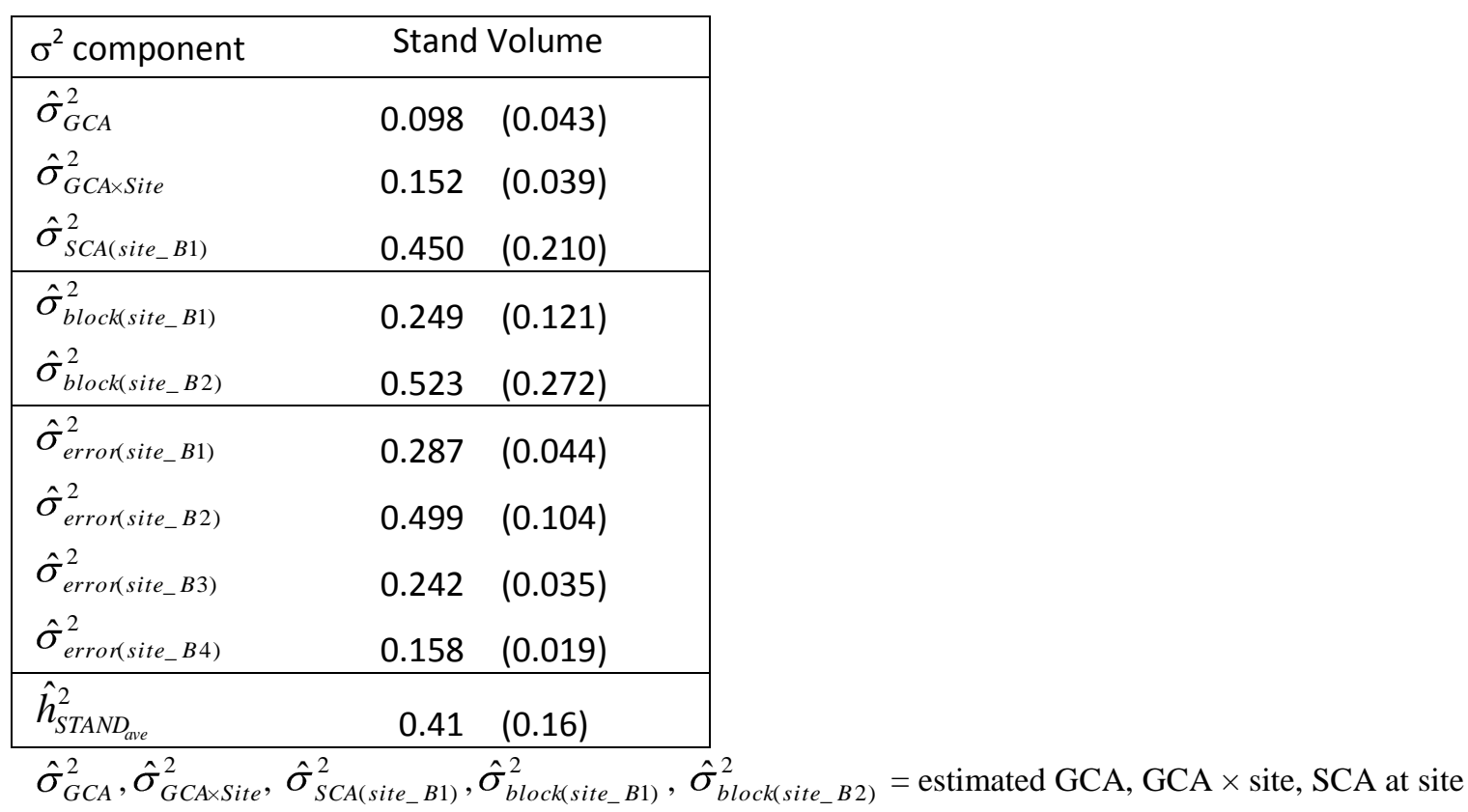

$12 \mathrm{~B} 1$, incomplete block at site B1, and incomplete block at site $\mathrm{B} 2$ variances, respectively;

$13 \hat{\sigma}_{\text {errorssite_B1) }}^{2}, \hat{\sigma}_{\text {error(sit__B2) }}^{2}, \hat{\sigma}_{\text {errorssit_BB3 }}^{2}, \hat{\sigma}_{\text {errorssite_B4) }}^{2}=$ estimated residual variances for sites B1, B2,

$14 \mathrm{~B} 3$, and B4, respectively; $\hat{h}_{S T A N D_{\text {we }}}^{2}=$ estimated average narrow-sense heritability for stand volume. 
1 Table 10. Uniform inter-site additive genetic correlations within and between plot types

2 at the site scale and between plot types at the regional scale. Estimated standard errors are

3 in parenthesis.

\begin{tabular}{|c|c|c|c|c|c|}
\hline \multirow[t]{2}{*}{ Traits } & \multirow[t]{2}{*}{ Plot } & \multicolumn{4}{|c|}{ Selection Traits } \\
\hline & & Height & DBH & Sectional & StemVol \\
\hline \multicolumn{6}{|c|}{ Uniform correlations at the site scale } \\
\hline Between-site & Line-plot & $0.88(0.05)$ & $0.73(0.09)$ & $0.71(0.09)$ & $0.82(0.07)$ \\
\hline Between-site stand & Block-plot & $0.45(0.13)$ & $0.44(0.13)$ & $0.44(0.13)$ & $0.45(0.13)$ \\
\hline Selection-stand & Line $v$ & $0.65(0.08)$ & $0.59(0.09)$ & $0.58(0.09)$ & $0.65(0.08)$ \\
\hline \multicolumn{6}{|c|}{ Single correlations between traits at the regional scale } \\
\hline Selection-stand & Line $v$ & $0.86(0.08)$ & $0.87(0.09)$ & $0.87(0.09)$ & $0.90(0.07)$ \\
\hline
\end{tabular}

4

5 Table 11. Predicted (BLUP-based) genetic gain for top-ranked families from four 3.5-

6 year selection traits in line-plot trials and realised (LSM) gain in stand volume for the

7 same families in late-rotation block-plots. Families were ranked by selection trait and

8 gains are expressed relative to the mean of 42 families which were represented by three

9 or more block-plots.

\begin{tabular}{|c|c|c|c|c|c|c|c|c|}
\hline \multirow{2}{*}{$\begin{array}{l}\text { Selection Trait }\left(C \hat{V}_{A}\right) \\
\text { Genetic gain }\end{array}$} & \multicolumn{2}{|c|}{ Height (0.073) } & \multicolumn{2}{|c|}{$\mathrm{DBH}(0.057)$} & \multicolumn{2}{|c|}{ Sectional area $(0.108)$} & \multicolumn{2}{|c|}{ Stem Volume $(0.141)$} \\
\hline & Predicted & Realised & Predicted & Realised & Predicted & Realised & Predicted & Realised \\
\hline Best 5 families (12\%) & $8.0 \%$ & $20.5 \%$ & $4.7 \%$ & $20.2 \%$ & $9.1 \%$ & $20.5 \%$ & $14.6 \%$ & $22.6 \%$ \\
\hline Best 21 families (50\%) & $4.3 \%$ & $7.7 \%$ & $2.5 \%$ & $6.6 \%$ & $4.9 \%$ & $7.1 \%$ & $7.4 \%$ & $7.1 \%$ \\
\hline
\end{tabular}

10 


\section{$1 \quad$ Figures}

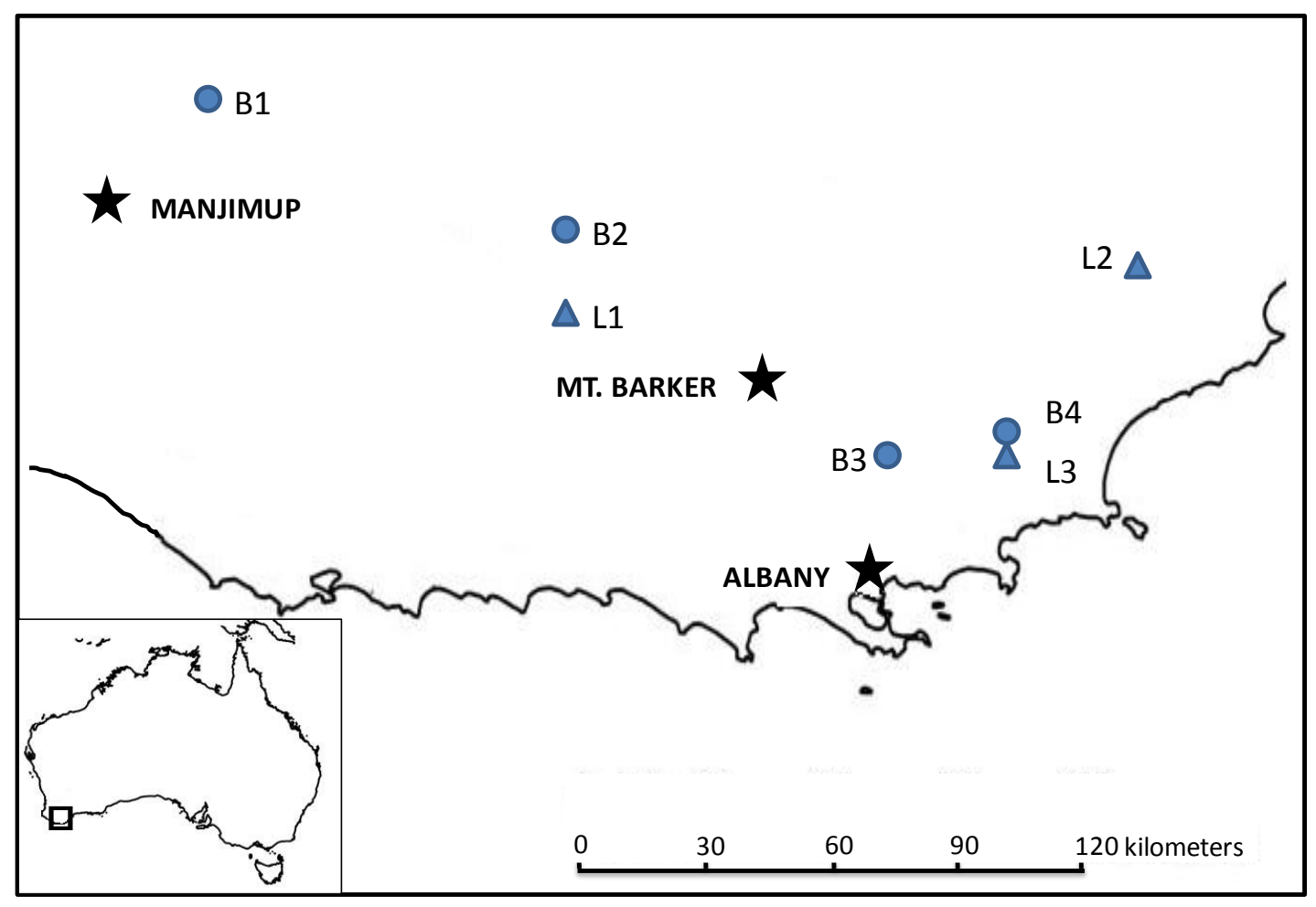

2

3 Figure 1. Map of the line-plot trial locations (triangles) and block-plot trial locations

4 (circles) relative to population centres in southern West Australia (stars).

5

6

7

8 


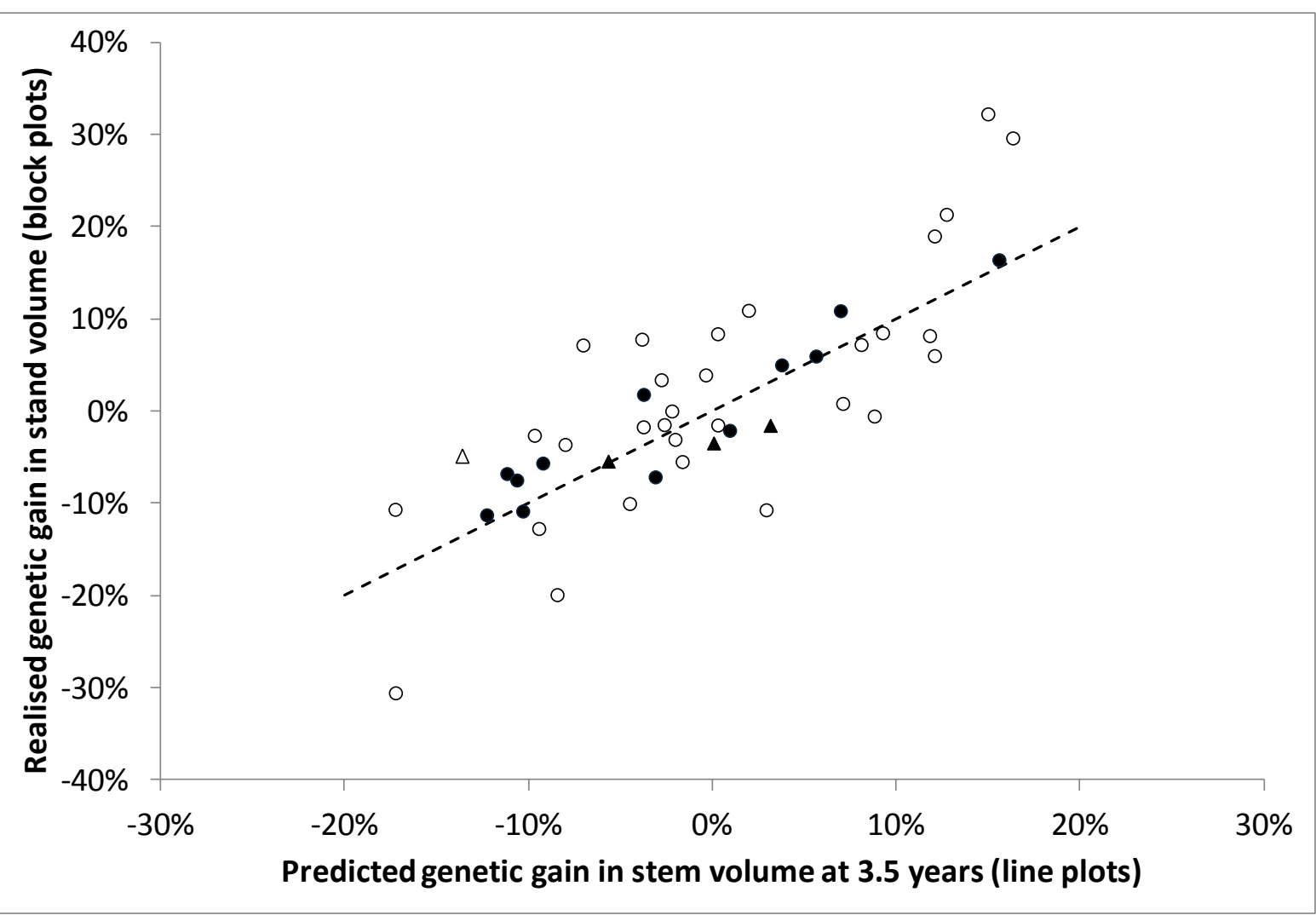

4 Figure 2. Relationship between realised genetic gain in stand volume of families in

5 block-plots (as a percentage of the site mean) and predicted genetic gain in stem volume

6 in line-plots at 3.5 years (as a percentage of the population mean on a site where $\mathrm{CV}_{\mathrm{A}}=$

7 0.141) for full-sib families (circles) and checks (triangles) represented by more than 10

8 block plots (solid symbols) and 3 to 10 block-plots (open symbols). The line represents

9 parity.

10

11

12

13 


\section{University Library}

\section{- M M N E R VA A gateway to Melbourne's research publications}

Minerva Access is the Institutional Repository of The University of Melbourne

Author/s:

Callister, AN;England, N;Collins, S

Title:

Predicted genetic gain and realised gain in stand volume of Eucalyptus globulus

Date:

2013-04-01

Citation:

Callister, A. N., England, N. \& Collins, S. (2013). Predicted genetic gain and realised gain in stand volume of Eucalyptus globulus. TREE GENETICS \& GENOMES, 9 (2), pp.361-375. https://doi.org/10.1007/s11295-012-0558-8.

Persistent Link:

http://hdl.handle.net/11343/282791 